Article

\title{
Fuzzy Sliding Mode Wheel Slip Ratio Control for Smart Vehicle Anti-Lock Braking System
}

\author{
Jinhong Sun $\mathbb{D}$, Xiangdang Xue $\mathbb{D}$ and Ka Wai Eric Cheng * $\mathbb{D}$ \\ Power Electronics Research Center, Department of Electrical Engineering, The Hong Kong Polytechnic \\ University, Hung Hom, Kowloon, Hong Kong, China \\ * Correspondence: eeecheng@polyu.edu.hk
}

Received: 7 June 2019; Accepted: 25 June 2019; Published: 28 June 2019

\begin{abstract}
With the development of in-wheel technology (IWT), the design of the electric vehicles (EV) is getting much improved. The anti-lock braking system (ABS), which is a safety benchmark for automotive braking, is particularly important. Installing the braking motor at each fixed position of the wheel improves the intelligent control of each wheel. The nonlinear ABS with robustness performance is highly needed during the vehicle's braking. The anti-lock braking controller (CAB) designed in this paper considered the well-known adhesion force, the resistance force from air and the wheel rolling friction force, which bring the vehicle model closer to the real situation. A sliding mode wheel slip ratio controller (SMWSC) is proposed to yield anti-lock control of wheels with an adaptive sliding surface. The vehicle dynamics model is established and simulated with consideration of different initial braking velocities, different vehicle masses and different road conditions. By comparing the braking effects with various $\mathrm{CAB}$ parameters, including stop distance, braking torque and wheel slip ratio, the SMWSC proposed in this paper has superior fast convergence and stability characteristics. Moreover, this SMWSC also has an added road-detection module, which makes the proposed braking controller more intelligent. In addition, the important brain of this proposed ABS controller is the control algorithm, which can be used in all vehicles' ABS controller design.
\end{abstract}

Keywords: anti-lock braking system (ABS); anti-lock braking controller (CAB); fuzzy control; PID control; sliding mode wheel slip ratio controller (SMWSC)

\section{Introduction}

The ABS is a very important safety component for vehicles because it is inevitable that an emergency situation will occur during the operation of a vehicle. When the braking force of wheel is greater than its road adhesion, the wheel of a vehicle without ABS will be locked and will start to skid. In addition, vehicles without ABS are prone to becoming locked under certain conditions of friction and speed, and then dangerous phenomena occur such as drift and even over-turn or turning around. Therefore, the design of ABS has always been the top priority of safe driving. The development of hydraulic ABS for fuel vehicles is relatively mature, but such hydraulic ABSs cannot be applied to electric vehicles (EV). With the world's awareness of energy conservation, EVs are considered as one of the most promising options for sustainable transportation systems [1], thus their performance improvement has become a hot research topic. With the new legislation on EV and the relative maturity in EV technology and lower cost in research and development of EV parts, the growth of EVs in the automotive market is increasing rapidly; therefore, the safe driving of EVs is worthy of research and development. Recently, some electro-hydraulic hybrid braking controllers for EVs have been studied, such as the novel electro-hydraulic braking system mentioned in [2,3]. However, the EV with a pure electronic based $\mathrm{CAB}$ contributed extensively to the world and is relatively new compared 
to the traditional hydraulic and electro-hydraulic braking systems. The electric braking system includes hybrid-electric and pure-electric and requires internal wheel control to support its flexible implementation [4-6]. High-performance motor drives [7] are extensively developed, which facilitates the development of EVs' ABS.

The braking system based on wheel control is widely used in nonlinear ABS controller design [8]. The principle of wheel control is that the four wheels of a vehicle are individually controlled by its independent controller via internal wheel motors [5]. Since the CAB directly controls a single wheel, it can respond quickly to disturbances and adjust the braking force to compensate for the effects from the disturbances. Several strategies have been proposed to design the $C A B$, such as logic threshold control, PID control, fuzzy PID control, etc. Due to the higher requirements of the nonlinear performance of $\mathrm{CAB}$ design, the controller with robustness and fault-tolerance stands out and becomes the main direction of ABS research. For instance, a fuzzy observer-based steering control method is proposed by Zhang [9], which uses the T-S fuzzy control [10] to build the fuzzy vehicle dynamics model. Wang et al. [11] described the adaptive robustness online constructive fuzzy control, which combines the adaptive decoupling function to improve the robustness performance.

A summary of several drawbacks of the recent popular anti-lock brake controllers (CABs) $[5,9,12]$ and shown in the following:

- These papers just consider a few well-known forces during vehicle dynamics analyses. Usually, one or two of the drag forces from air and the wheel rolling friction force are ignored, which leads to unrealistic model building.

- During the simulation, the initial control point is given as zero (for, e.g., wheel slip ratio and braking torque) and the simulation does not consider disturbances that exist during vehicle braking, which makes the control situation too simple and does not meet the actual situation.

- In these $C A B$ designs, road conditions during braking simulations are all given as the known parameters, which do not match the actual braking situation.

The fuzzy control algorithm is a reasoning mechanism that is essentially a method based on the designer's experience. Its advantage is that no accurate system mathematical model is needed, and the designer can yield better control performance according to the experience of various working states. However, the control effect depends entirely on the designer's experience, which means that the parameter adjustment process will be very complicated as the vehicle's braking state increases. The key point is that the $\mathrm{CAB}$ based on the simple fuzzy control algorithm finds it difficult to meet the robustness requirements of the vehicle braking process when there are many uncertainties. Therefore, a sliding mode control algorithm is added, the main working principle of which is to ensure that the control state enters the pre-set sliding surface by continuously switching the control amount. This pre-set sliding surface can keep the control performance stable when encountering parameter disturbances and external disturbances, which ensures that the sliding mode-based CAB will meet the control requirements of the vehicle braking process.

To yield a more realistic and reliable vehicle model, and further lay out the foundation for verifying the control characteristics of the proposed $\mathrm{CAB}$ algorithm, more practical factors have been considered:

- As we all know, when the wheel is in the anti-lock state, there must exist the wheel rolling friction force. Besides, when the vehicle is running, it must withstand air resistance. Under normal circumstances, this air drag force is positively related to the vehicle's velocity. Therefore, the vehicle model establishment here contains both the drag force from air and the wheel rolling friction force.

- In the case of real vehicle braking, it should be that when the wheel slip rate is too high and there is a risk of locking, the ABS starts to control the wheel to maintain the anti-lock state. Therefore, it is impossible to start vehicle braking from the point where the wheel slip ratio is zero. To make the whole vehicle braking period more reasonable and further service the verification of this CAB's control performance, select the wheel slip ratio 0.8 as the initial braking point of all simulations. 
- As a rule of thumb, when the ABS starts to operate, the initial control point is also affected by the vehicle model parameters themselves, that is, the speed displayed on the vehicle's meter is not the initial speed of the brake. For this reason, during this simulation model, the vehicle initial drive state reflected by vehicle parameters are also considered.

Based on the analyses mentioned above, this new realistic vehicle model is built, which further helps to make subsequent proposed controllers' control performance verification more reliable. Besides, an optimal SMWSC is proposed in this paper, based on the wheel slip ratio control, to realize the optimal slip ratio control of wheels during the vehicle's braking. In addition, the proposed ABS design does not include a road condition automatic detection module, which is critical for automotive braking processes. Even though some automotive ECUs include a road condition monitoring mechanism, there will be a delay once it is detected and transmitted to the ABS, which will further lead to very serious consequences. The ABS with a road condition automatic detection module will largely reduce the delay time and increase the control accuracy. Therefore, in this ABS module design, the road automatic detection part is added, which largely improves the intelligence of the proposed ABS controller and makes it more novel. Moreover, the variables and parameters of this proposed SMWSC and vehicle model are based on BYD's electric vehicle: BYD F0. Besides, this paper is conducted under the EV project, so the title, content and further experiments are mainly based on EV. In other words, this kind of ABS controller can be used in the latest and most difficult electric vehicles, not to mention other cars.

The main contributions can be summaries as below:

- More realistic forces which can affect the braking effect to varying degrees are added.

- The whole control is made to start with difficult initial braking situations, which restores the actual car brakes as much as possible; for instance, the initial braking wheel slip ratio is set as 0.8 at dry roads; the initial vehicle braking state is related to this time's vehicle velocity.

- The road condition automatic detection module is added, which can give the road condition and improve the control accuracy and intelligence.

After the introduction, this paper introduces the analyses of vehicle dynamics, which should be considered as the theoretical basis of the CAB design, in detail in Section 2. In this section, some necessary conditions for designing the controller are also given, such as road conditions and control object of the proposed controller. Then the design flow of the controller is described in detail around this control object in Section 3. To better describe the control process, this section first analyses the state of the vehicle during braking and then selects one case to give a detailed description. Then simulation results are given in Section 4. In this section, the vehicle real test module is firstly established, based on the vehicle dynamics mentioned in Section 2, which operates during the whole braking period, that is, the road condition automatic detection period and ABS control period. Then, separately, the design of the road condition detection module and the SMWSC module are given. Besides, different control comparisons on different types of CABs, different road conditions and different uncertain disturbances are all given in the results part. Finally, Section 5 gives the conclusion.

\section{Vehicle Dynamics}

In order to design a more realistic and reliable ABS controller, the vehicle dynamic model considered as the cornerstone must be established. As the car braking process is ever-changing, the straight-line vehicle braking case is firstly chosen as a more common phenomenon for analysis. The force applied to the vehicle by tires, gravity and aerodynamics are considered in this vehicle dynamics; besides this, the drag force from air $\left(0.5 \times \rho \cdot C_{a i r} \cdot A_{a i r} \cdot v_{v_{x}}{ }^{2}\right)$ and the resistance force derived from the wheel rolling friction are also considered in this vehicle model to make the constructed vehicle more realistic.

In addition, it is assumed that the road condition keeps unchanged during the whole vehicle braking period and the wear on tires is ignored, which means all four wheels are in the same 
situation. Therefore, the dynamic equation of a single wheel and a whole vehicle can be obtained in Equation (1) [12,13]; besides this, parameters are defined in Table A1.

According to the magic formula (Tire-Road Interaction), which was firstly proposed by Pacejka [10], the relationship between the longitudinal wheel slip ratio $\lambda$ and the friction coefficient of the road $\mu$ is shown in Figure $1[14,15]$. Several key points of these typical road conditions are based on Figure 1, and are summarized and shown in Table 1.

$$
\left\{\begin{array}{l}
J \cdot \dot{\omega}_{w}=F_{f f w} \cdot R_{w}+(1-\lambda) \cdot F_{r f w} \cdot R_{w}-T_{b w} \\
M \cdot \dot{v}_{v_{x}}=-4 F_{f f w}-4(1-\lambda) \cdot F_{r f w}-F_{a i r}
\end{array}\right.
$$

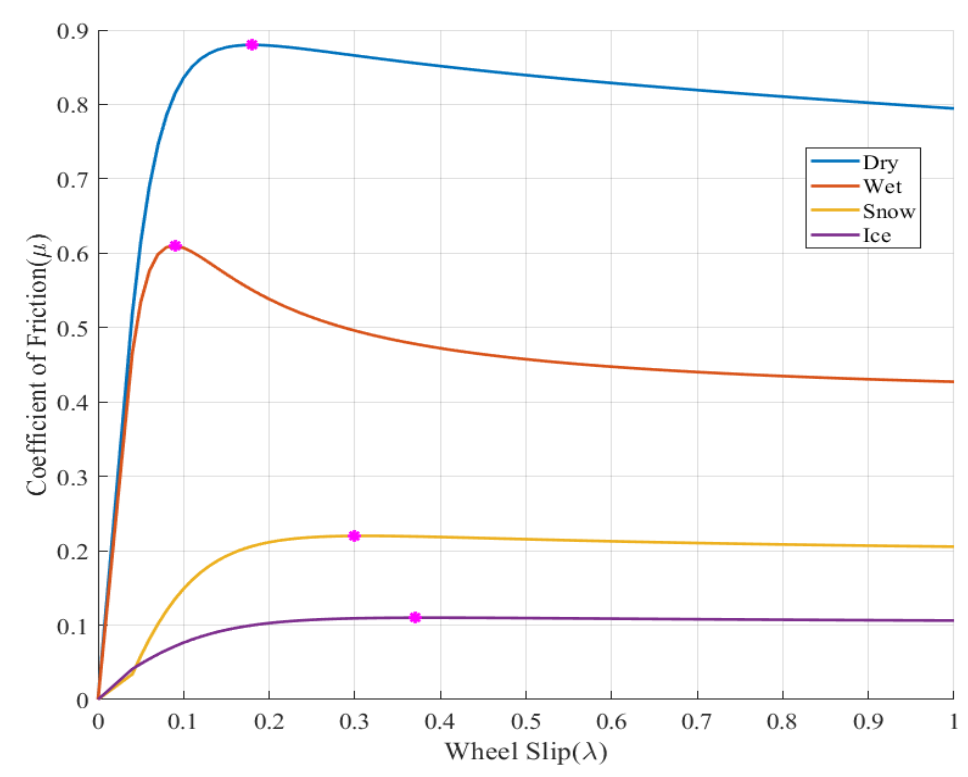

Figure 1. The relationship between $\lambda$ and $\mu$.

Table 1. Several key points of $\mu(\lambda)$ curve.

\begin{tabular}{cccc}
\hline Road Condition & Slip Ratio (Optimal) & Coefficient (Maxmium) & Coefficient (Slip Ratio = 1) \\
\hline Dry & 0.18 & 0.8800 & 0.7945 \\
Wet & 0.09 & 0.6099 & 0.4272 \\
Snow & 0.3 & 0.2200 & 0.2055 \\
Ice & 0.37 & 0.1100 & 0.1062 \\
\hline
\end{tabular}

For the vehicle braking model, $\lambda$ is defined as the real-time wheel slip ratio, which is calculated based on the vehicle velocity, and $\dot{\lambda}$ is the dynamics of the wheel slip ratio.

$$
\begin{aligned}
& \lambda=\frac{v_{v_{x}}-\omega_{w} R_{w}}{v_{v_{x}}}=1-\frac{\omega_{w} R_{w}}{v_{v_{x}}} \\
& \dot{\lambda}=-\frac{1}{v_{v_{x}}}\left[\dot{\omega}_{w} R_{w}-\dot{v}_{v_{x}}(1-\lambda)\right]
\end{aligned}
$$

Combining Equations (1) and (2), the $\dot{\lambda}$ can be described with vehicle parameters and shown in Equation (3).

$$
\begin{array}{r}
\dot{\lambda}=-\frac{1}{v_{v_{x}}}\left[\frac{\mu M g}{4 m_{w}}+\left(\frac{\mu_{r f} M g}{4 m_{w}}+\mu g+\mu_{r f} g(1-\lambda)+\frac{0.34 v_{v_{x}}^{2}}{M}\right)\right. \\
(1-\lambda)]+\frac{T_{b w}}{v_{v_{x}} m_{w} R_{w}}
\end{array}
$$




\section{Design of Sliding Mode Wheel Slip Ratio Controller}

\subsection{Four Wheels Joint Control for Straight Line Case}

Based on the assumptions mentioned in the previous section, the vehicle is driving on a horizontal road with a straight-line situation, which driving state is shown in Figure 2. In this figure, $v_{v_{x}}$ and $v_{v_{y}}$ are the vehicle's longitudinal and lateral velocities; $(m / s), F_{y_{f_{L}}}, F_{y_{f_{R}}}, F_{y_{r_{L}}}$ and $F_{y_{r_{R}}}$ are the wheel's longitudinal force $(N) ; F_{x_{f_{L}}}, F_{x_{f_{R}}}, F_{x_{r_{L}}}$ and $F_{x_{r_{R}}}$ are the wheel's lateral force $(N) ; \gamma$ is the yaw rate of the vehicle and $M_{z}$ is the center of mass [16,17]. Besides, $w$ is the spacing between left and right wheels and $l_{f}$ and $l_{r}$ are the distance from $M_{z}$ to the front and rear axles.

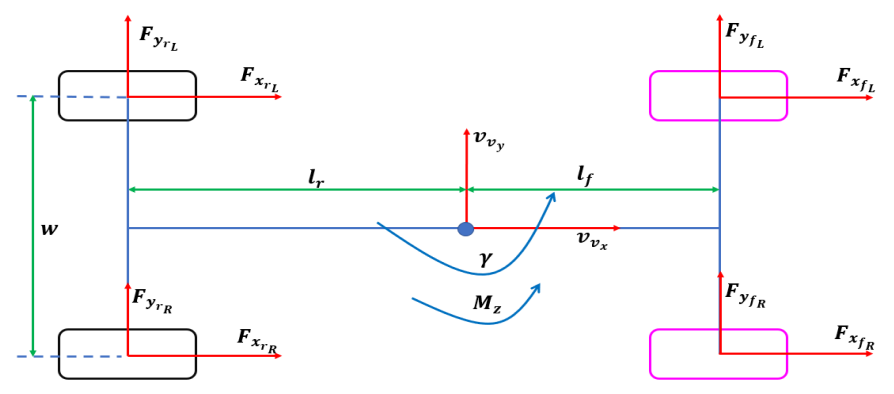

Figure 2. Real vehicle model.

The vehicle's motion equation can be described in Equation (4) $[18,19]$.

$$
\left\{\begin{array}{l}
M \cdot a_{x}=F_{x_{f_{l}}}+F_{x_{f_{r}}}+F_{x_{r_{l}}}+F_{x_{r_{r}}} \\
M \cdot a_{y}=F_{y_{f_{l}}}+F_{y_{f_{r}}}+F_{y_{f_{l}}}+F_{y_{r_{r}}} \\
M z=\left(F_{x_{r_{r}}}-F_{x_{r_{l}}}\right) \frac{w}{2}+\left(F_{x_{f_{r}}}-F_{x_{f_{l}}}\right) \frac{w}{2}
\end{array}\right.
$$

Based on the principle of axle load proportional distribution shown in Equation (5), the longitudinal force of every wheel is obtained in Equation (6) [17,20]. For this case, controlling all four wheels with unlock situations separately can ensure the steering wheel is under a controllable state.

$$
\begin{gathered}
\left\{\begin{array}{l}
F_{L_{f}}=\frac{M\left(g l_{r}-a_{x} h\right)}{l_{r}+l_{f}} \\
F_{L_{f}}=\frac{M\left(g l_{f}+a_{x} h\right)}{l_{r}+l_{f}}
\end{array}\right. \\
\left\{\begin{array}{l}
F_{w 1}=\frac{F_{L_{f}}\left(M a_{x}-\frac{2 M_{z}}{d}\right)}{2 M g} \\
F_{w 2}=\frac{F_{L_{f}}\left(M a_{x}+\frac{2 M_{z}}{d}\right)}{2 M g} \\
F_{w 3}=\frac{F_{L_{r}}\left(M a_{x}-\frac{2 M_{z}}{d}\right)}{2 M g} \\
F_{w 4}=\frac{F_{L_{r}}\left(M a_{x}+\frac{2 M_{z}}{d}\right)}{2 M g}
\end{array}\right.
\end{gathered}
$$

\subsection{The Wheel Braking Torque Module}

In this section, the SMWSC is proposed to yield safe and fast braking standards, especially the safety one. As it is known, all four wheels operate under a braking state when the vehicle starts to brake. Therefore, controlling the operation of every single wheel in the anti-lock state during the vehicle brake ensures that the steering wheel can be flexibly controlled. The control mechanism of the SMWSC is built based on the control object mentioned above and shown in Equation (7).

$$
T_{b w}=\dot{\lambda} v_{v_{x}} m_{w} R_{w}+m_{w} R_{w}\left[\frac{\mu M g}{4 m_{w}}+\left(\frac{\mu_{r f} M g}{4 m_{w}}+\mu g+\mu_{r f} g(1-\lambda)+\frac{0.34 v^{2}}{M}\right)(1-\lambda)\right]
$$


In the straight-line case mentioned in Figure 2, every single wheel operates under the same situation. We select the front left wheel as an example to show the control details, for which the control flow is shown in Figure 3. The main operating principle is to control the vehicle to approximate the optimal wheel slip ratio of different road conditions within the controllable range of the slip ratio. The wheel braking torque $T_{b w}$, which is the output variable of SMWSC, mainly works on adjusting the wheel angular velocity to control the wheel slip ratio in an optimal changing trend during the SMWSC control period for vehicle braking [21,22].

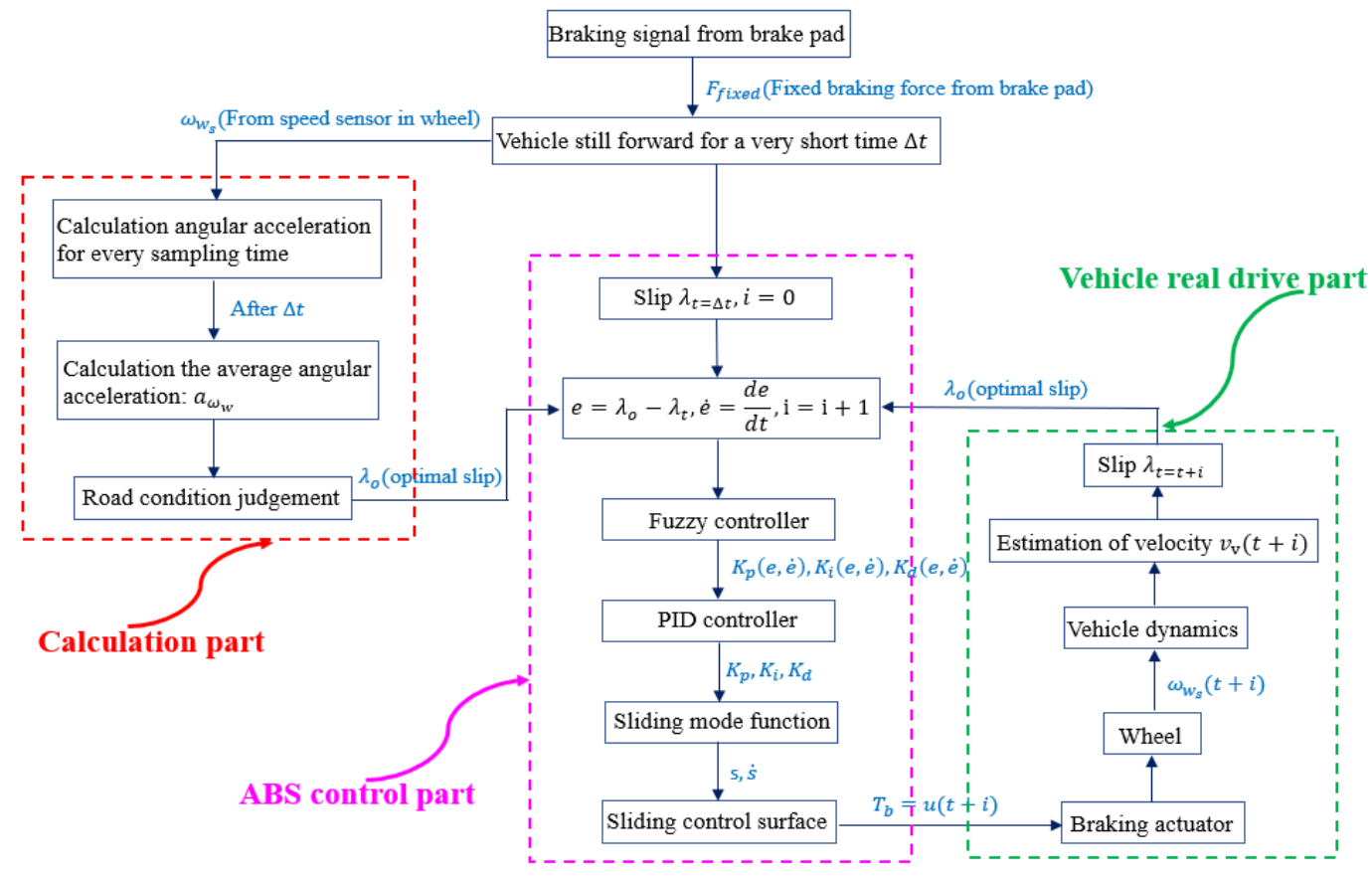

Figure 3. Control flow for single wheel.

\subsection{The Fuzzy Part of the SMWSC}

Shown as Figure 3, after the SMWSC starts working, the wheel slip ratio first enters the fuzzy control phase. Define the error and error change rate of wheel slip ratio as $e=\lambda_{o}-\lambda$ and $\dot{e}=\dot{\lambda_{o}}-\dot{\lambda}$, where $\lambda_{o}$ is the optimal vehicle slip ratio of different road conditions at the maximum road friction coefficient mentioned in Table 1. The Takagi-Sugeuo-Kang (TSK) fuzzy system [23] is added to yield the robustness performance, the input and output variables of which are defined in Equation $(8)[24,25]$.

$$
\left\{\begin{array}{l}
e=N B, N M, N S, Z O, P S, P M, P B \\
\dot{e}=N B, N M, N S, Z O, P S, P M, P B \\
k_{p, i, d(e, \dot{e})}=N B, N M, N S, Z O, P S, P M, P B
\end{array}\right.
$$

where, $N$ means negative, $P$ means positive, $B$ means big, $M$ means middle, $S$ means small and $Z O$ means zero. Therefore, NB, NM, NS, ZO, PS, PM and PB stand for the level.

Rules of this fuzzy inference system (FIS) are defined based on Equation (9) [26], where, $k_{p}, k_{i}$ and $k_{d}$ are weighted values of $K_{p(e, \dot{e})}, K_{i(e, \dot{e})}$ and $K_{d(e, \dot{e})}$ in different states.

$$
\left\{\begin{array}{l}
K_{p(e, \dot{e})}=\frac{\sum_{i=1}^{7} \mu_{i}(|e|,|\dot{e}|) k_{p}}{\sum_{i=1}^{7} \mu_{i}(|e|,|\dot{e}|)} \\
K_{i(e, \dot{e})}=\frac{\sum_{i=1}^{7} \mu_{i}(|e|,|\dot{e}|) k_{i}}{\sum_{i=1}^{7} \mu_{i}(|e|,|\dot{e}|)} \\
K_{d(e, \dot{e})}=\frac{\sum_{i=1}^{j=1} \mu_{i}(|e|,|\dot{e}|) k_{d}}{\sum_{i=1}^{7} \mu_{i}(|e|,|\dot{e}|)}
\end{array}\right.
$$


Actually, the fuzzy control module and PID control module are considered as the compound fuzzy PID controller. The output variables of the fuzzy controller, $k_{p}(e, \dot{e}), k_{i}(e, \dot{e})$ and $k_{d}(e, \dot{e})$, are then put through the PID control module and become the final output variables of the fuzzy PID controller, shown in Equation (10).

$$
\left\{\begin{array}{l}
K_{p}=k_{p_{0}} \times k_{p(e, \dot{e})} \times k_{p_{1}} \\
K_{i}=k_{i_{0}} \times k_{i(e, \dot{e})} \times k_{i_{1}} \\
K_{d}=k_{d_{0}} \times k_{d(e, e)} \times k_{d_{1}}
\end{array}\right.
$$

The definitions can be described as follows:

- $\quad k_{p_{0}}, k_{i_{0}}$ and $k_{d_{0}}$ are initial PID variables of the fuzzy PID controller.

- $\quad k_{p_{1}}, k_{i_{1}}$ and $k_{d_{1}}$ are correction PID variables of the fuzzy PID controller.

- $\quad K_{p}, K_{i}$ and $K_{d}$ are final output variables of the fuzzy PID controller.

\subsection{The Sliding Mode Part of the SMWSC}

While the above control parts have certain adaptive and robustness abilities, their stability is still not good enough, especially under uncertain disturbances. To solve this problem, this proposed CAB is defined with the sliding mode control, which lets the control operate in a defined sliding surface and keeps the control easier. To design the sliding mode control, assume the control system has uncertain interference $I(t)$; thus, the control function can be described as:

$$
\dot{\lambda}=f(\lambda)+b(\mu(t)+I(t)) \Longrightarrow I(t)=\frac{\dot{\lambda}-f(\lambda)}{b}-u(t)
$$

Obviously, $\frac{\mu_{r f} M g}{4 m_{w}}>>\mu_{r f}(1-\lambda) g$ [27]; thus, Equation (3) can be simplified as shown in Equation (12).

$$
\dot{\lambda}=-\frac{1}{v_{v_{x}}}\left[\frac{\mu M g}{4 m_{w}}+\left(\frac{\mu_{r f} M g}{4 m_{w}}+\mu g+\frac{0.34 v_{v_{x}}^{2}}{M}\right)(1-\lambda)\right]+\frac{T_{b w}}{v_{v_{x}} m_{w} R_{w}}
$$

Based on these two equations, two definitions can be obtained:

$$
\left\{\begin{array}{l}
f(\lambda)=-\frac{1}{v_{v_{x}}}\left[\frac{\mu M g}{4 m_{w}}+\left(\frac{\mu_{r f} M g}{4 m_{w}}+\mu g+\frac{0.34 v_{v_{x}}^{2}}{M}\right)(1-\lambda)\right] \\
b=\frac{1}{v_{v_{x}} m_{w} R_{w}}
\end{array}\right.
$$

The sliding mode modules are defined in Equation (14), where $s$ is the sliding surface.

$$
\left\{\begin{array}{l}
s=e+K_{p} \int e+K_{i} \iint e+K_{d} e \\
\dot{s}=\dot{e}+K_{p} e+K_{i} \int e+K_{d} \dot{e}
\end{array}\right.
$$

According to the exponential approach law in Equation (15), the control object of this proposed SMWSC can be described as in Equation (16).

$$
\begin{gathered}
\dot{s}=-\varepsilon(t) \operatorname{sgn}(s)-I(t) \\
u(t)=\frac{1}{b}\left(\dot{\lambda_{o}}-f(\lambda)+(b-1) \dot{e}\right)+K_{p} e+K_{i} \int e+K_{d} \dot{e}+\varepsilon(t) \operatorname{sgn}(s)
\end{gathered}
$$

Based on the stability function Lyapunov $v=\frac{1}{2} s^{2}$, we can get:

$$
\begin{gathered}
\dot{v}=s \dot{s}=s(-\varepsilon(t) \operatorname{sgn}(s)-I(t))=-\varepsilon(t)|s|-I(t) s<0 \\
\varepsilon(t)>|I(t)|
\end{gathered}
$$


where $\varepsilon(t)$ is the compensation of an uncertain part, which is used to judge whether the sliding mode existence condition is satisfied. Using the integral method to estimate the upper bound of $\varepsilon(t)$, then Equation (16) can be described as in Equation (20).

$$
\begin{gathered}
\hat{\varepsilon}(t)=\eta \int_{0}^{t} \Delta \varepsilon d t \\
u(t)=\frac{1}{b}\left(\dot{\lambda_{o}}-f(\lambda)+(b-1) \dot{e}\right)+K_{p} e+K_{i} \int e+K_{d} \dot{e}+\hat{\varepsilon}(t) \operatorname{sgn}(s)
\end{gathered}
$$

The fuzzy rule of sliding mode is proposed: When $s \dot{s}>0, \hat{\varepsilon}(t)$ needs to be increased and when $s \dot{s}<0, \hat{\varepsilon}(t)$ needs to be decreased.

\section{Simulation}

\subsection{Establishment of the Vehicle model and the Control Module}

This section shows the simulation part contains the vehicle model establishment based on the vehicle dynamics mentioned in Section 2 and the ABS control modules based on Section 3.

The braking situation is consideration a straight-line case. The initial condition is set as wheel slip ratio $\lambda_{\text {initial }}=0.8$ on dry road, and simulation results are chosen at initial vehicle velocity $v_{0}=100 \mathrm{~km} / \mathrm{h}$. In addition, the force initial states influenced by the vehicle initial braking velocity, such as wheel rolling friction force and air resistant force, are considered.

Besides, this simulation is built based on the logic of the formula of the road condition curve, this curve is further improved and the curve shift disturbances are simulated to verify the robustness performance of this proposed ABS controller when resisting these curve changes. The drawback may be that only four typical road conditions are considered.

Firstly, select the front left wheel as an example to build the real test module. Before SMWSC starts, the vehicle is driven with the road condition automatic detection module under a fixed braking force during a short calculation period $\Delta t=0.029 \mathrm{~s}$, shown in the left of Figure 4 . This short calculation period is the vehicle's earliest braking stable time obtained through a short training [28] on different road conditions with different initial braking velocities. After the calculation part of this module, shown in Figure 3, the road condition is determined then given to the ABS control module. The outputs of the road condition automatic detection module are $\lambda_{o}, v_{v}$ and $\omega_{w}$, which are also considered as the input variables of the ABS controller's input variables.

Figure 4 shows the entire brake control process, which is based on the control flow shown in Figure 3 and contains two stages: The road automatic detection period and the ABS control period.
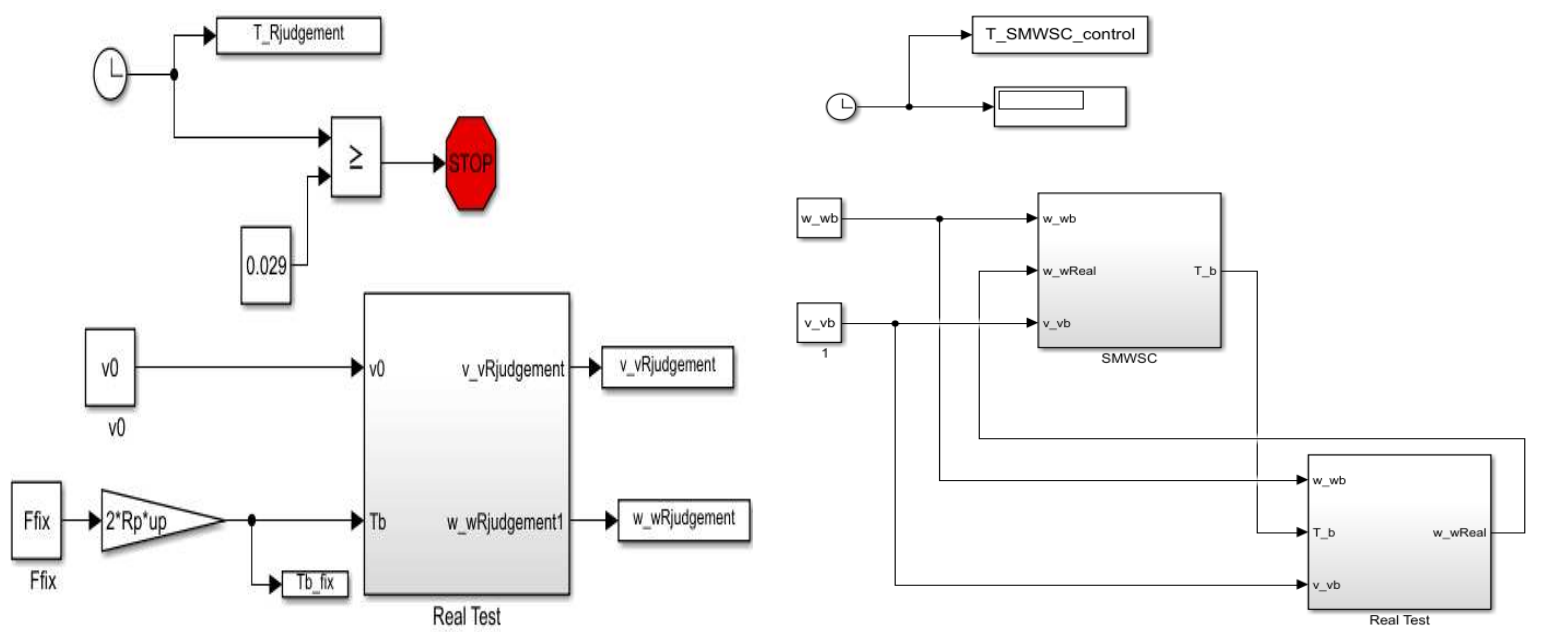

Figure 4. The whole braking process: The road automatic detection period and the ABS control period. 


\subsection{Simulation Results and Discussions}

There have many indicators that measure the control performance of the ABS controller during the whole vehicle braking period; select the three most important options: The stop distance $D$ is considered as the parameter that is finally displayed, the braking torque $T_{b w}$ is the guarantee of the automobile motor's lifetime and the wheel real-time slip ratio $\lambda$ is the steering wheel controllable sign. The initial vehicle braking velocities $v_{0}=30 \mathrm{~km} / \mathrm{h}, 40 \mathrm{~km} / \mathrm{h}, 50 \mathrm{~km} / \mathrm{h}, 60 \mathrm{~km} / \mathrm{h}, 70 \mathrm{~km} / \mathrm{h}, 80 \mathrm{~km} / \mathrm{h}$, $90 \mathrm{~km} / \mathrm{h}$ and $100 \mathrm{~km} / \mathrm{h}$ are all tested in this simulation. Besides, all simulations are simulated with different classic road conditions: Dry, wet, snow and ice roads.

This subsection first gives a comparison of the braking control performance of the vehicle with different types of ABS controllers: Normal PID-based CAB, improved PID-based CAB, fuzzy PID-based $\mathrm{CAB}$ and fuzzy sliding mode PID-based CAB. PID parameters used in these four CABs are set as the same values and shown in Table 2. Considering that using the real-time data will largely increase the complexity of the analysis and using average data can largely show the trend of data, the comparison data used in the following three figures are all average values.

Table 2. PID parameters for different CABs.

\begin{tabular}{ccccccc}
\hline CAB Type & & Kp & & Ki & & Kd \\
\hline Normal PID & & 544 & & 1 & & 750 \\
Improved PID & & 544 & & 1 & & 750 \\
\hline & Kp0 & Kp1 & Ki0 & Ki1 & Kd0 & Kd1 \\
\hline Fuzzy PID & 68 & 8 & 10 & 0.1 & 25 & 30 \\
Fuzzy sliding Mode & 68 & 8 & 10 & 0.1 & 25 & 30 \\
\hline
\end{tabular}

Figures 5-7 show $D, T_{b w}$ and $\lambda$ control performance comparison of different types of CABs on different road conditions with different initial vehicle velocities, separately.

Figure 5 show clearly the stop distance comparison:

- $\quad$ The improved PID-based CAB has a little shorter $D$ on dry road compared with a normal PID-based CAB. However, the $D$ of the improved PID-based CAB is slightly longer than the normal PID-based CAB on snow roads and ice roads with all the initial vehicle velocities.

- The stop distance of the two robustness type CABs are much shorter than the pure PID-based CABs on dry, wet, snow and ice roads with all the initial vehicle velocities.

- $\quad$ The fuzzy PID-based CABs have longer stop distance compared with fuzzy sliding mode based-CABs on all four road conditions with all the initial vehicle velocities, especially on dry roads.

Figure 6 shows clearly the braking torque comparison:

- $\quad$ The braking torque of a normal PID-based CAB is the largest one on all the four road conditions with all the initial vehicle velocities compared with the other three types of CABs. Besides, $T_{b w}$ of this normal PID-based CAB on dry and wet roads is very similar and is also very similar on snow roads and ice roads.

- $\quad$ The braking torque of the improved PID-based CAB is different on different road conditions with different initial vehicle velocities. Moreover, the improved PID-based CAB needs larger braking torque compared to the two robustness $\mathrm{CABs}$, on almost all four kinds roads with different initial vehicle velocities.

- The two robustness CABs, fuzzy PID-based CAB and fuzzy sliding mode-based CAB, need smaller braking torque compared with pure PID-based CABs on all road conditions with all initial vehicle velocities. 


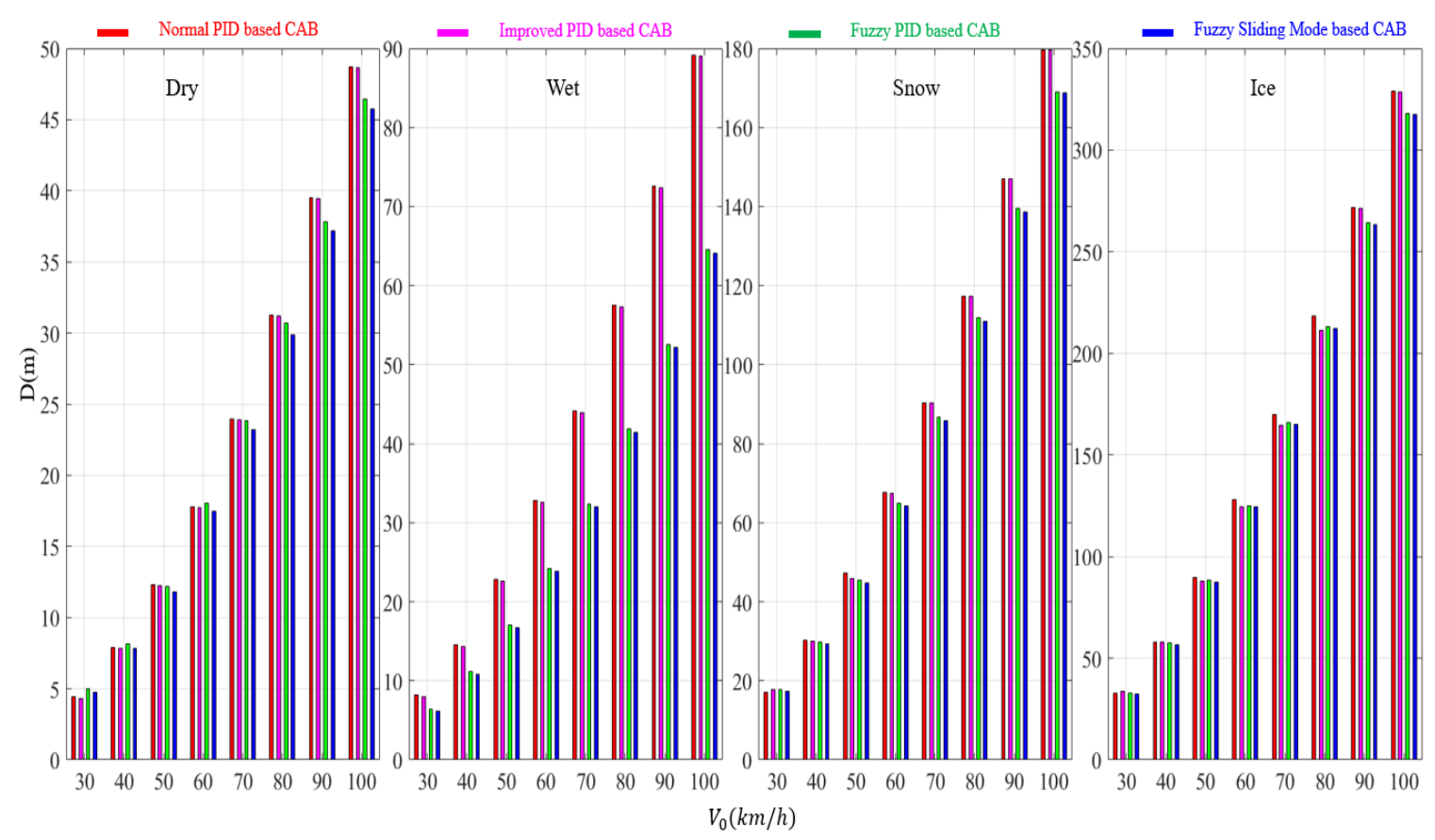

Figure 5. The $D$ comparison under different $C A B s$ on various road conditions.

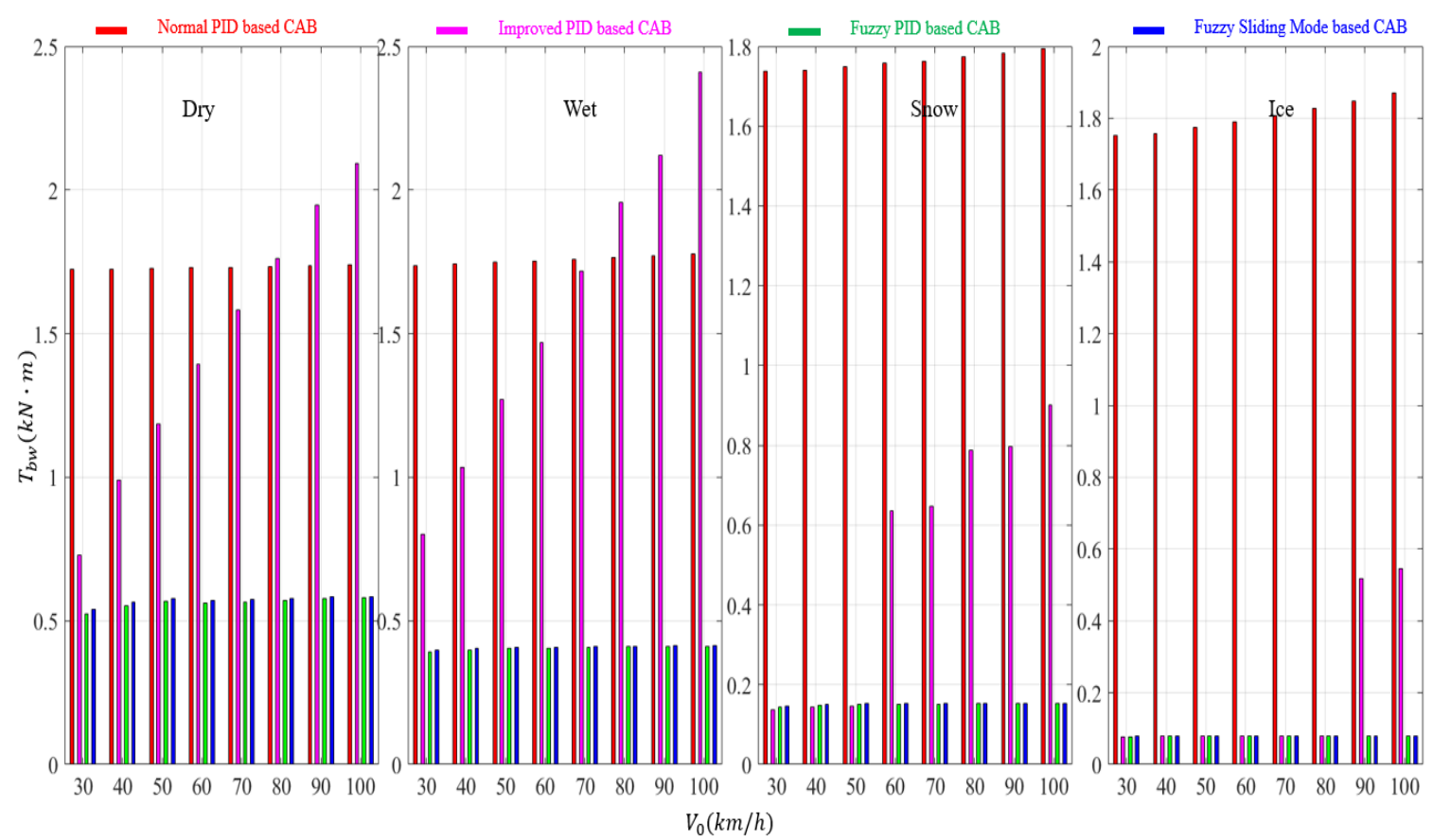

Figure 6. The $T_{b w}$ comparison under different $C A B s$ on various road conditions.

Figure 7 show real-time wheel slip ratio comparison clearly:

- The wheel slip ratio of normal PID-based CABs is almost 1 on all road conditions with all initial vehicle velocities.

- The wheel slip ratio of improved PID-based CABs is close to 1 on dry and wet roads with all initial vehicle velocities. Besides, the wheel slip ratio of improved PID-based CABs is almost equal to 1 on snow roads with $70 \mathrm{~km} / \mathrm{h}, 80 \mathrm{~km} / \mathrm{h}, 90 \mathrm{~km} / \mathrm{h}$ and $100 \mathrm{~km} / \mathrm{h}$ and on ice roads with $90 \mathrm{~km} / \mathrm{h}$ and $100 \mathrm{~km} / \mathrm{h}$.

- The wheel slip ratios of the two robustness CABs are small enough on all the four road conditions with all initial vehicle velocities compared with the other two pure PID-based CABs. In addition, 
the wheel slip ratios of these two robustness CABs are around 0.1 on dry and wet roads and around 0.3 on snow roads and ice roads; these slip ratios are all closer to the optimal slip ratio of different roads.

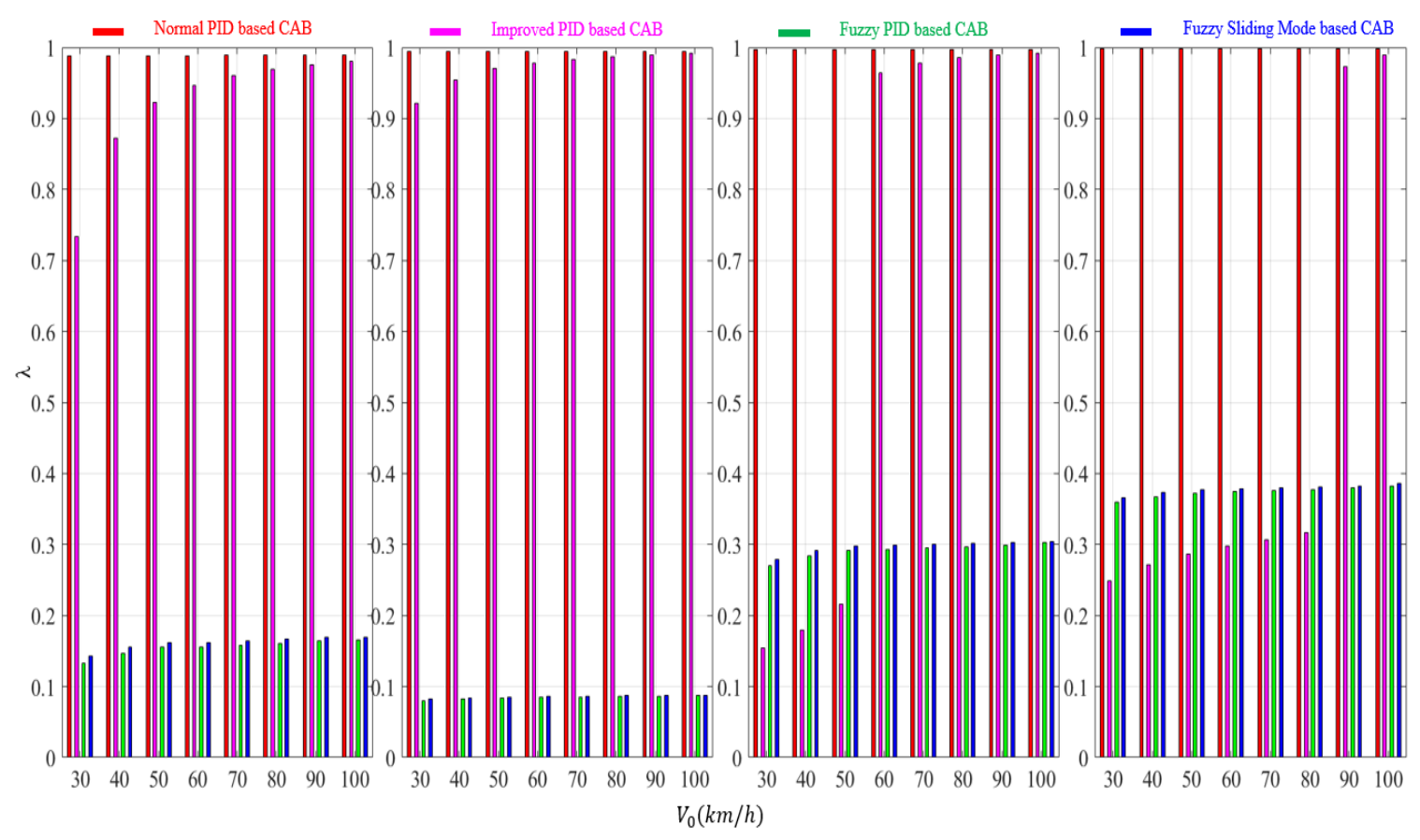

Figure 7. The $\lambda$ comparison under different CABs on various road conditions.

The conclusion obtained from the analysis in Figure 5 is that the two robustness CABs have good braking control performance, as they can make the vehicle brake quickly. In Figure 6, the pure PID-based CABs need higher braking torque and are almost unadjustable, which largely increases the energy loss and shortens the vehicle's lifetime. In contrast, the robustness CABs require very little braking torque and can be flexibly adjusted for different road conditions. Figure 7 shows the control performance analysis of wheel stability during vehicle braking. The wheel under control of pure PID CABs will quickly lock on all four road conditions with all velocities. However, the wheel under robustness $\mathrm{CABs}$ will maintain an anti-lock state during whole braking period.

From the analyses mentioned above, the only conclusion that can be drawn is that the robustness CABs have more prominent control performances. In order to better show the proposed SMWSC's control advantages, the wheel real-time slip ratio and braking torque regulation on dry, wet, snow and ice roads are given in Figure 8. The large image represents the entire braking process and the small image highlights the stage of the initial adjustment. Through the comparison of $\lambda$ and $T_{b w}$, especially with the small images, the proposed SMWSC is verified to have better convergence and stability.

As is well known, once the ABS controller starts working, a set of operating parameters is fixed in SMWSC as the initial braking parameter. When the actual situation changes, the ABS controller will adjust the braking torque according to the feedback signal from the vehicle real test module. To have a deep study of SMWSC's dependence on the road conditions and vehicle parameters during its control period, the following figures and tables are shown. 

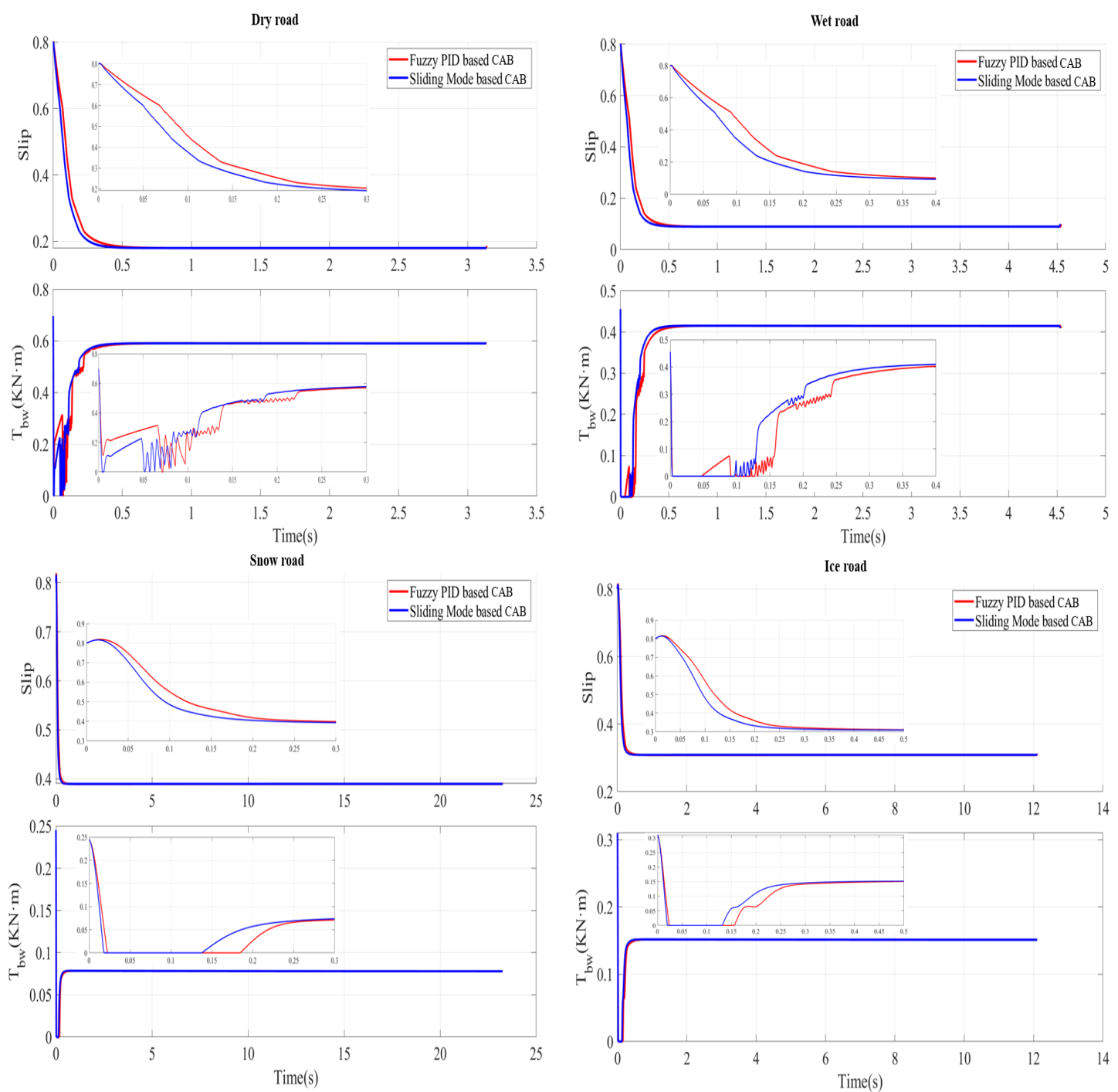

Figure 8. The whole sliding mode wheel slip ratio controller (SMWSC)-based braking process on different road conditions with $v_{0}=100 \mathrm{~km} / \mathrm{h}$.

For the road condition disturbances, the $\mu(\lambda)$ curve shifting left and right represents the road type change and moving up and down stands for the rough level change of road. Figure 9 shows the curve $\mu(\lambda)$ shifts left and right significantly on different road conditions, separately. In this figure, the original unchanged curve is the black line $s$, other curves shift around this curve: $s 1=0.8$ and $s 2=0.9$ shift to the right and $s 3=1.1$ and $s 4=1.2$ shift to the left. Table 3 gives the results data, where $D_{S}$ is the original stop distance and $D_{S_{i}}, i=1,2,3,4$ is the stop distance when the vehicle drives on the changed curve; thus, $\left|D_{S}-D_{S_{i}}\right|$ is the control difference of the stop distance. Besides, $T_{S}$ is the original average braking torque and $T_{S_{i}}, i=1,2,3,4$ is the braking torque required by the ABS controller when the vehicle is driven on the corresponding road condition curve; thus, $\left|T_{S}-T_{S_{i}}\right|$ is the control difference of the stop distance. In addition, select $30 \mathrm{~km} / \mathrm{h}, 60 \mathrm{~km} / \mathrm{h}, 80 \mathrm{~km} / \mathrm{h}$ and $100 \mathrm{~km} / \mathrm{h}$ to show comparison details.

From the comparison data shown in Table 3, we can obtain that:

- On dry roads, the $\left|D_{S}-D_{S_{i}}\right|$ keeps within $0.4 \mathrm{~m}$ even if the curve shifts left and right; the largest one is $0.375 \mathrm{~m}$ at $100 \mathrm{~km} / \mathrm{h}$. Correspondingly, the braking torque required by the ABS controller under these road conditions is similar and its difference remains within $5 \mathrm{~N} \cdot \mathrm{m}$. 
- On wet roads, the $\left|D_{S}-D_{S_{i}}\right|$ keeps within $0.8 \mathrm{~m}$ and the largest one is $0.784 \mathrm{~m}$ at $100 \mathrm{~km} / \mathrm{h}$. To yield the small $\left|D_{S}-D_{S_{i}}\right|$, the ABS controller will greatly adjust the braking torque, for example, $\left|T_{S}-T_{S_{i}}\right|=27.627 \mathrm{~N} \cdot \mathrm{m}$ under $s 4$ road conditions.

- On snow roads, the $\left|D_{S}-D_{S_{i}}\right|$ keeps within $1.8 \mathrm{~m}$; most difference remains below $1 \mathrm{~m}$. Correspondingly, the braking torque required by the ABS controller under these road conditions is similar and its difference remains within $1.9 \mathrm{~N} \cdot \mathrm{m}$.

- On ice roads, the $\left|D_{S}-D_{S_{i}}\right|$ keeps within $2.1 \mathrm{~m}$; this data is below $0.6 \mathrm{~m}$ under $s 2, s 3$ and $s 4$. The braking torque required by the ABS controller under these road conditions is similar and its difference remains within $1 \mathrm{~N} \cdot \mathrm{m}$.

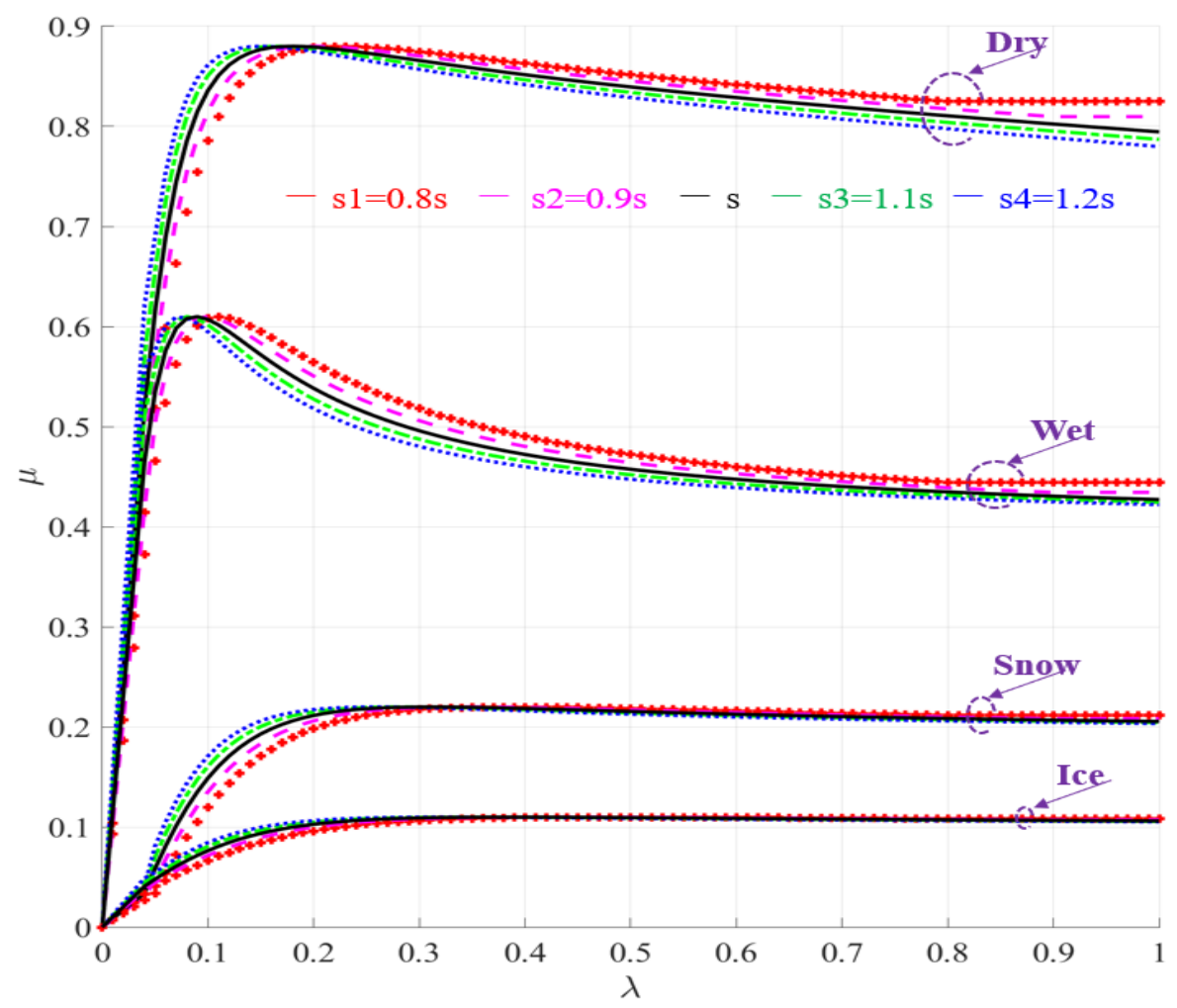

Figure 9. The horizontal change of the curve $\mu(\lambda)$.

Therefore, we can get the conclusion that this road condition change has little impact on braking control performance under SMWSC, which further verifies that this proposed SMWSC has enough abilities to adjust braking torque to resist these kinds of disturbances.

Table 3 gives the results data, where $D_{S}$ is the original stop distance, $D_{S_{i}}$ and $i=1,2,3,4$ is the stop distance when vehicle drives on the changed curve; thus, $\left|D_{S}-D_{S_{i}}\right|$ is the control difference of the stop distance. Besides, $T_{S}$ is the original average braking torque and $T_{S_{i}}, i=1,2,3,4$ is the braking torque required by the $\mathrm{ABS}$ controller when the vehicle is driven on the corresponding road condition curve; thus, $\left|T_{S}-T_{S_{i}}\right|$ is the control difference of the stop distance. In addition, select $30 \mathrm{~km} / \mathrm{h}$, $60 \mathrm{~km} / \mathrm{h}, 80 \mathrm{~km} / \mathrm{h}$ and $100 \mathrm{~km} / \mathrm{h}$ to show comparison details.

Figure 10 shows the curve $\mu(\lambda)$ moves up and down significantly on different road conditions, separately. In this figure, the original unchanged curve is the black line $\mu$, other curves are moved around this curve: $u 1=0.8$ and $u 2=0.9$ move down and $u 3=1.1$ and $u 4=1.2$ move up. Table 4 gives the result details of $D$ and $T_{b w}$ regulations, where definitions of $\left|D_{u}-D_{u_{i}}\right|$ and $\left|T_{u}-T_{u_{i}}\right|$ are similar to Table 3 . In addition, select $30 \mathrm{~km} / \mathrm{h}, 60 \mathrm{~km} / \mathrm{h}, 80 \mathrm{~km} / \mathrm{h}$ and $100 \mathrm{~km} / \mathrm{h}$ to show comparison details. 
Table 3. $E_{\text {distance }}$ and $E_{T_{b w}}$ with $d_{s_{i}},(i=1,2,3,4)$.

\begin{tabular}{|c|c|c|c|c|c|c|c|c|c|}
\hline Road & Velocity $(\mathrm{km} / \mathrm{h})$ & s1 & s2 & s3 & s4 & s1 & s2 & s3 & s4 \\
\hline & & \multicolumn{4}{|c|}{$\left|D_{s}-D_{s_{i}}\right|(m)$} & \multicolumn{4}{|c|}{$\left|T_{S}-T_{S_{i}}\right|(N \cdot m)$} \\
\hline \multirow{4}{*}{ Dry } & 30 & 0.051 & 0.026 & 0.019 & 0.036 & 4.148 & 2.008 & 1.311 & 2.164 \\
\hline & 60 & 0.232 & 0.101 & 0.064 & 0.111 & 4.968 & 2.092 & 1.017 & 1.520 \\
\hline & 80 & 0.352 & 0.137 & 0.094 & 0.067 & 4.554 & 1.724 & 0.847 & 0.278 \\
\hline & 100 & 0.375 & 0.157 & 0.126 & 0.189 & 3.524 & 1.371 & 0.731 & 0.870 \\
\hline \multirow{4}{*}{ Wet } & 30 & 0.084 & 0.035 & 0.0173 & 0.031 & 7.057 & 3.263 & 0.302 & 0.297 \\
\hline & 60 & 0.324 & 0.129 & 0.003 & 0.234 & 8.193 & 3.727 & 2.435 & 17.215 \\
\hline & 80 & 0.525 & 0.191 & 0.084 & 0.700 & 8.332 & 3.612 & 6.568 & 23.827 \\
\hline & 100 & 0.784 & 0.278 & 0.237 & 1.384 & 8.451 & 3.604 & 9.277 & 27.627 \\
\hline \multirow{4}{*}{ Snow } & 30 & 0.211 & 0.126 & 0.074 & 0.126 & 1.440 & 0.745 & 0.377 & 0.560 \\
\hline & 60 & 1.096 & 0.520 & 0.157 & 0.202 & 1.830 & 0.778 & 0.173 & 0.052 \\
\hline & 80 & 1.444 & 0.527 & 0.211 & 0.186 & 1.556 & 0.529 & 0.115 & 0.118 \\
\hline & 100 & 1.791 & 0.567 & 0.083 & 0.008 & 1.387 & 0.418 & 0.026 & 0.485 \\
\hline \multirow{4}{*}{ Ice } & 30 & 0.452 & 0.174 & 0.107 & 0.174 & 0.806 & 0.295 & 0.143 & 0.182 \\
\hline & 60 & 1.312 & 0.515 & 0.163 & 0.221 & 0.670 & 0.234 & 0.039 & 0.024 \\
\hline & 80 & 1.772 & 0.582 & 0.173 & 0.092 & 0.592 & 0.181 & 0.014 & 0.082 \\
\hline & 100 & 2.035 & 0.572 & 0.007 & 0.374 & 0.514 & 0.136 & 0.034 & 0.189 \\
\hline
\end{tabular}

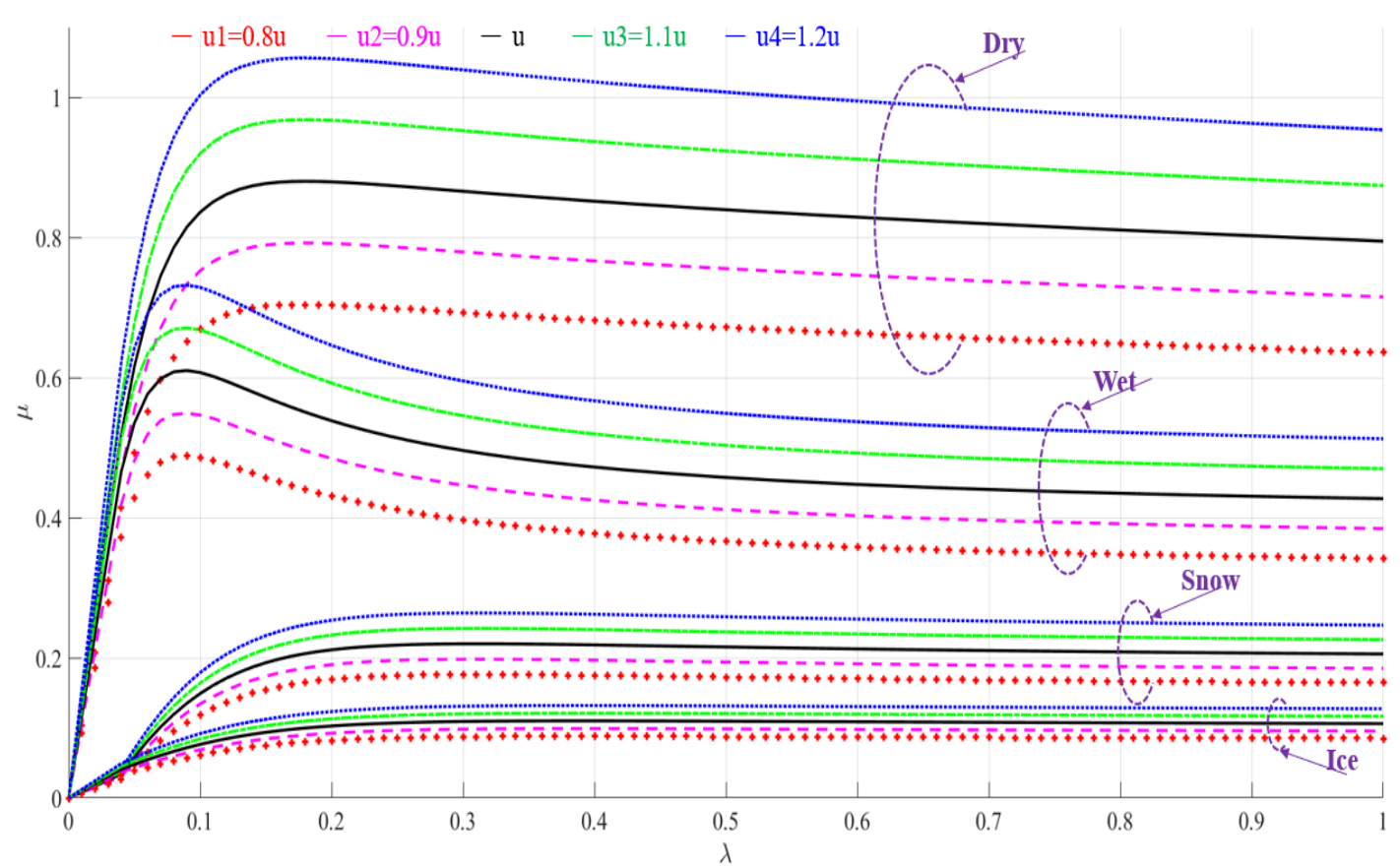

Figure 10. The vertical change of the curve $\mu(\lambda)$.

From the comparison data shown in Table 4, we can obtain that:

- On dry roads, the $\left|D_{u}-D_{u_{i}}\right|$ with $100 \mathrm{~km} / \mathrm{h}$ is $11.7115 \mathrm{~m}$, others remain below $8 \mathrm{~m}$. In addition, the braking torque adjustment is relatively strong; the largest one is $132.868 \mathrm{~N} \cdot \mathrm{m}$ on $u 1$ road with $100 \mathrm{~km} / \mathrm{h}$.

- On wet roads, $\left|D_{u}-D_{u_{i}}\right|$ increases and $\left|T_{u}-T_{u_{i}}\right|$ also increases. The largest one is $(28.489 \mathrm{~m}$, $149.386 \mathrm{~N} \cdot \mathrm{m}$ ) on $u 1$ road with $100 \mathrm{~km} / \mathrm{h}$.

- On snow roads, $\left|D_{u}-D_{u_{i}}\right|$ and $\left|T_{u}-T_{u_{i}}\right|$ all have large values; the largest one is $(18.399 \mathrm{~m}$, $17.9476 \mathrm{~N} \cdot \mathrm{m}$ ) on $u 2$ road with $100 \mathrm{~km} / \mathrm{h}$.

- On ice roads, $\left|D_{u}-D_{u_{i}}\right|$ and $\left|T_{u}-T_{u_{i}}\right|$ still have large values, the largest $\left|D_{u}-D_{u_{i}}\right|$ is $62.336 \mathrm{~m}$ on $u 1$ road with $100 \mathrm{~km} / \mathrm{h}$, the largest $\left|T_{u}-T_{u_{i}}\right|$ is $17.146 \mathrm{~N} \cdot \mathrm{m}$ on $u 1$ road with $80 \mathrm{~km} / \mathrm{h}$. 
Table 4. $E_{\text {distance }}$ and $E_{T_{b w}}$ with $d_{u_{i}}(i=1,2,3,4)$.

\begin{tabular}{|c|c|c|c|c|c|c|c|c|c|}
\hline Road & Velocity $(\mathrm{km} / \mathrm{h})$ & u1 & $\mathbf{u} 2$ & u3 & u4 & u1 & $\mathbf{u} 2$ & u3 & $\mathbf{u} 4$ \\
\hline & & \multicolumn{4}{|c|}{$\left|D_{u}-D_{u_{i}}\right|(m)$} & \multicolumn{4}{|c|}{$\left|T_{u}-T_{u_{i}}\right|(N \cdot m)$} \\
\hline \multirow{4}{*}{ Dry } & 30 & 0.969 & 0.423 & 0.174 & 241 & 108.17 & 54.94 & 4.93 & 4.523 \\
\hline & 60 & 4.276 & 1.885 & 0.801 & 1.151 & 125.64 & 65.566 & 3.246 & 3.584 \\
\hline & 80 & 7.577 & 3.338 & 1.435 & 1.991 & 130.14 & 68.273 & 2.882 & 2.445 \\
\hline & 100 & 11.7115 & 5.203 & 2.263 & 3.288 & 132.868 & 70.107 & 2.764 & 3.346 \\
\hline \multirow{4}{*}{ Wet } & 30 & 2.461 & 1.198 & 0.135 & 0.174 & 134.356 & 87.944 & 0.753 & 0.478 \\
\hline & 60 & 10.490 & 5.185 & 0.612 & 0.813 & 145.51 & 97.557 & 0.756 & 0.759 \\
\hline & 80 & 18.441 & 9.164 & 1.096 & 1.469 & 148.07 & 99.965 & 0.780 & 0.916 \\
\hline & 100 & 28.489 & 14.218 & 1.713 & 2.308 & 149.386 & 101.259 & 0.821 & 0.994 \\
\hline \multirow{4}{*}{ Snow } & 30 & 3.925 & 1.741 & 1.021 & 1.601 & 30.378 & 15.534 & 4.828 & 6.457 \\
\hline & 60 & 16.261 & 7.293 & 4.088 & 6.404 & 33.750 & 17.582 & 2.932 & 4.086 \\
\hline & 80 & 1.444 & 12.199 & 7.034 & 11.080 & 1.444 & 17.676 & 2.604 & 3.731 \\
\hline & 100 & 1.791 & 18.399 & 10.957 & 17.179 & 1.791 & 17.947 & 2.631 & 3.749 \\
\hline \multirow{4}{*}{ Ice } & 30 & 7.814 & 3.463 & 2.364 & 3.822 & 16.318 & 8.303 & 3.475 & 3.91 \\
\hline & 60 & 29.870 & 13.339 & 8.899 & 14.688 & 17.044 & 8.778 & 2.361 & 3.021 \\
\hline & 80 & 49.098 & 21.925 & 14.790 & 24.439 & 17.146 & 8.841 & 2.202 & 2.917 \\
\hline & 100 & 62.336 & 31.022 & 21.643 & 35.926 & 16.312 & 8.749 & 2.175 & 2.999 \\
\hline
\end{tabular}

Obviously, the change of $\mu$ has a little bit of an influence on control performance, especially on snow and ice roads. It can also be seen from Figure 1, that even a slight change of $\mu$ can have a large difference on $\lambda$. In other words, the ABS controller needs to increase the modulation intensity to a large extent to meet the trend of $\mu$ change. Therefore, this proposed ABS controller's robustness ability to handle this disturbance is not strong enough.

For the vehicle parameters disturbances, this paper only considers the most common factor vehicle mass $\mathrm{M}$ here. Table 5 shows the comparison results, $M$ is the original vehicle mass is unchanged and $0.9 \mathrm{M}$ means the vehicle mass decreases to $90 \% \mathrm{M}$, while $1.1 \mathrm{M}, 1.2 \mathrm{M}$ and $1.3 \mathrm{M}$ denote that the vehicle mass increase; besides, $\left|D_{M}-D_{M_{\text {change }}}\right|$ is the stop distance difference. $\left|T_{M}-T_{M_{\text {change }}}\right|$ is the braking torque difference.

Table 5. $E_{\text {distance }}$ and $E_{T_{b w}}$ with $d_{M}$.

\begin{tabular}{|c|c|c|c|c|c|c|c|c|c|}
\hline Road & Velocity (km/h) & $0.9 \mathrm{M}$ & $1.1 \mathrm{M}$ & $1.2 \mathrm{M}$ & $1.3 \mathrm{M}$ & $0.9 \mathrm{M}$ & $1.1 \mathrm{M}$ & $1.2 \mathrm{M}$ & $1.3 \mathrm{M}$ \\
\hline & & \multicolumn{4}{|c|}{$\left|D_{M}-D_{M_{\text {change }}}\right|(m)$} & \multicolumn{4}{|c|}{$\left|T_{M}-T_{M_{\text {change }}}\right|(N \cdot m)$} \\
\hline \multirow{4}{*}{ Dry } & 30 & 0.0281 & 0.0281 & 0.0558 & 0.0852 & 35.547 & 35.291 & 70.141 & 104.265 \\
\hline & 60 & 0.0287 & 0.0321 & 0.0734 & 0.1015 & 38.981 & 38.814 & 77.266 & 115.682 \\
\hline & 80 & 0.0623 & 0.0462 & 0.1845 & 0.2312 & 39.513 & 39.595 & 77.951 & 116.678 \\
\hline & 100 & 0.0828 & 0.071 & 0.1483 & 0.2151 & 40.131 & 40.111 & 78.55 & 118.545 \\
\hline \multirow{4}{*}{ Wet } & 30 & 0.0239 & 0.0235 & 0.0487 & 0.0759 & 26.801 & 26.385 & 52.177 & 77.218 \\
\hline & 60 & 0.0336 & 0.037 & 0.0762 & 0.1119 & 28.073 & 27.918 & 55.436 & 82.724 \\
\hline & 80 & 0.0702 & 0.0738 & 0.1637 & 0.2556 & 28.351 & 27.342 & 53.129 & 78.953 \\
\hline & 100 & 0.1148 & 0.185 & 0.397 & 0.5904 & 28.63 & 24.779 & 48.528 & 72.852 \\
\hline \multirow{4}{*}{ Snow } & 30 & 0.0604 & 0.0711 & 0.1235 & 0.2117 & 9.919 & 9.813 & 19.621 & 29.168 \\
\hline & 60 & 0.0101 & 0.1437 & 0.2571 & 0.1295 & 10.616 & 10.417 & 20.822 & 31.348 \\
\hline & 80 & 0.3614 & 0.3282 & 0.6731 & 0.9365 & 10.481 & 10.445 & 20.04 & 30.623 \\
\hline & 100 & 0.7817 & 0.3994 & 1.0853 & 1.6434 & 10.539 & 10.57 & 19.545 & 30.375 \\
\hline \multirow{4}{*}{ Ice } & 30 & 0.0453 & 0.0467 & 0.0967 & 0.136 & 5.371 & 5.37 & 10.724 & 16.092 \\
\hline & 60 & 0.3358 & 0.388 & 0.6646 & 0.9685 & 5.443 & 5.408 & 10.835 & 16.242 \\
\hline & 80 & 1.2232 & 1.0938 & 2.0462 & 2.9035 & 5.391 & 5.379 & 10.751 & 16.114 \\
\hline & 100 & 2.6274 & 2.3443 & 4.4511 & 8.2676 & 5.394 & 5.343 & 10.665 & 15.989 \\
\hline
\end{tabular}

From the comparison data shown in Table 5, we can obtain that: 
- On dry roads, $\left|D_{M}-D_{M_{\text {change }}}\right|$ and $\left|T_{M}-T_{M_{\text {change }}}\right|$ are all very small; the largest $\left|D_{M}-D_{M_{\text {change }}}\right|$ is $0.2312 \mathrm{~m}$ with $1.3 \mathrm{M}$ and $80 \mathrm{~km} / \mathrm{h}$; the largest $\left|T_{M}-T_{M_{\text {change }}}\right|$ is $118.545 \mathrm{~N} \cdot \mathrm{m}$ with $1.3 \mathrm{M}$ and $100 \mathrm{~km} / \mathrm{h}$

- On wet roads, $\left|D_{M}-D_{M_{\text {change }}}\right|$ are all below $0.6 \mathrm{~m}$; the largest $\left|D_{M}-D_{M_{\text {change }}}\right|$ is $0.5904 \mathrm{~m}$ with $1.3 \mathrm{M}$ and $100 \mathrm{~km} / \mathrm{h}$; the largest $\left|T_{M}-T_{M_{\text {change }}}\right|$ is $82.724 \mathrm{~N} \cdot \mathrm{m}$ with $1.3 \mathrm{M}$ and $60 \mathrm{~km} / \mathrm{h}$

- On snow roads, $\left|D_{M}-D_{M_{\text {change }}}\right|$ are all below $1.7 \mathrm{~m}$; the largest $\left|D_{M}-D_{M_{\text {change }}}\right|$ is $1.6434 \mathrm{~m}$ with $1.3 \mathrm{M}$ and $100 \mathrm{~km} / \mathrm{h}$; the largest $\left|T_{M}-T_{M_{\text {change }}}\right|$ is $118.545 \mathrm{~N} \cdot \mathrm{m}$ with $1.3 \mathrm{M}$ and $60 \mathrm{~km} / \mathrm{h}$

- On ice roads, $\left|D_{M}-D_{M_{\text {change }}}\right|$ are all below $8.5 \mathrm{~m}$; the largest $\left|D_{M}-D_{M_{\text {change }}}\right|$ is $8.2676 \mathrm{~m}$ with $1.3 \mathrm{M}$ and $100 \mathrm{~km} / \mathrm{h}$; the largest $\left|T_{M}-T_{M_{\text {change }}}\right|$ is $118.545 \mathrm{~N} \cdot \mathrm{m}$ with $1.3 \mathrm{M}$ and $60 \mathrm{~km} / \mathrm{h}$.

It is clear that, even though the $\left|D_{M}-D_{M_{\text {change }}}\right|$ is near $8.5 \mathrm{~m}$ on ice roads with $1.3 \mathrm{M}$ and $100 \mathrm{~km} / \mathrm{h}$, it still can be considered as relatively small compared to the real stop distance shown in Figure 5 . Therefore, the conclusion can be obtained that the SMWSC has enough robustness to overcome the change effect of vehicle mass on dry, wet and snow roads.

All the above results are given based on known road conditions; however, the road condition is unknown when the vehicle is driven during the braking period. Therefore, the road detection module is added to improve road condition automatic detection performance of SMWSC.

Figure 11 shows the changes in integral action parameters inside the fuzzy PID control module. As all know, the parameters of the conventional PID controller are fixed after the controller's design; however, PID parameters are designed with the adaptive capability after being combined with the fuzzy control part. Figure 12 shows the adaptive changes of the wheel slip ratio error $e=\lambda_{o}-\lambda_{t}$ and $d e$; besides, Figure 13 shows the output parameters of the fuzzy control module.
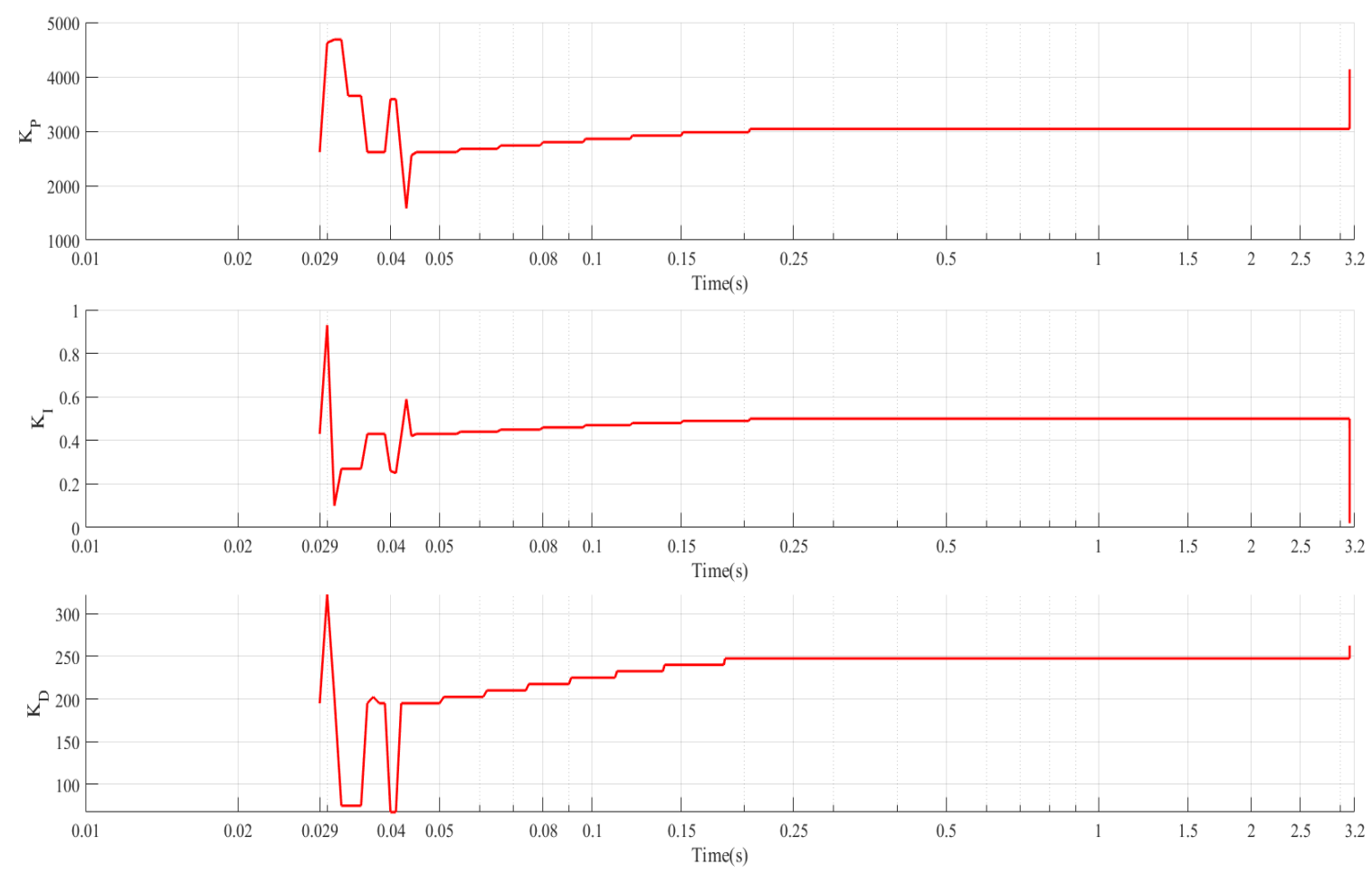

Figure 11. Fuzzy-PID control output parameters: $K_{P}, K_{I}$ and $K_{D}$ with adaptive capability. 

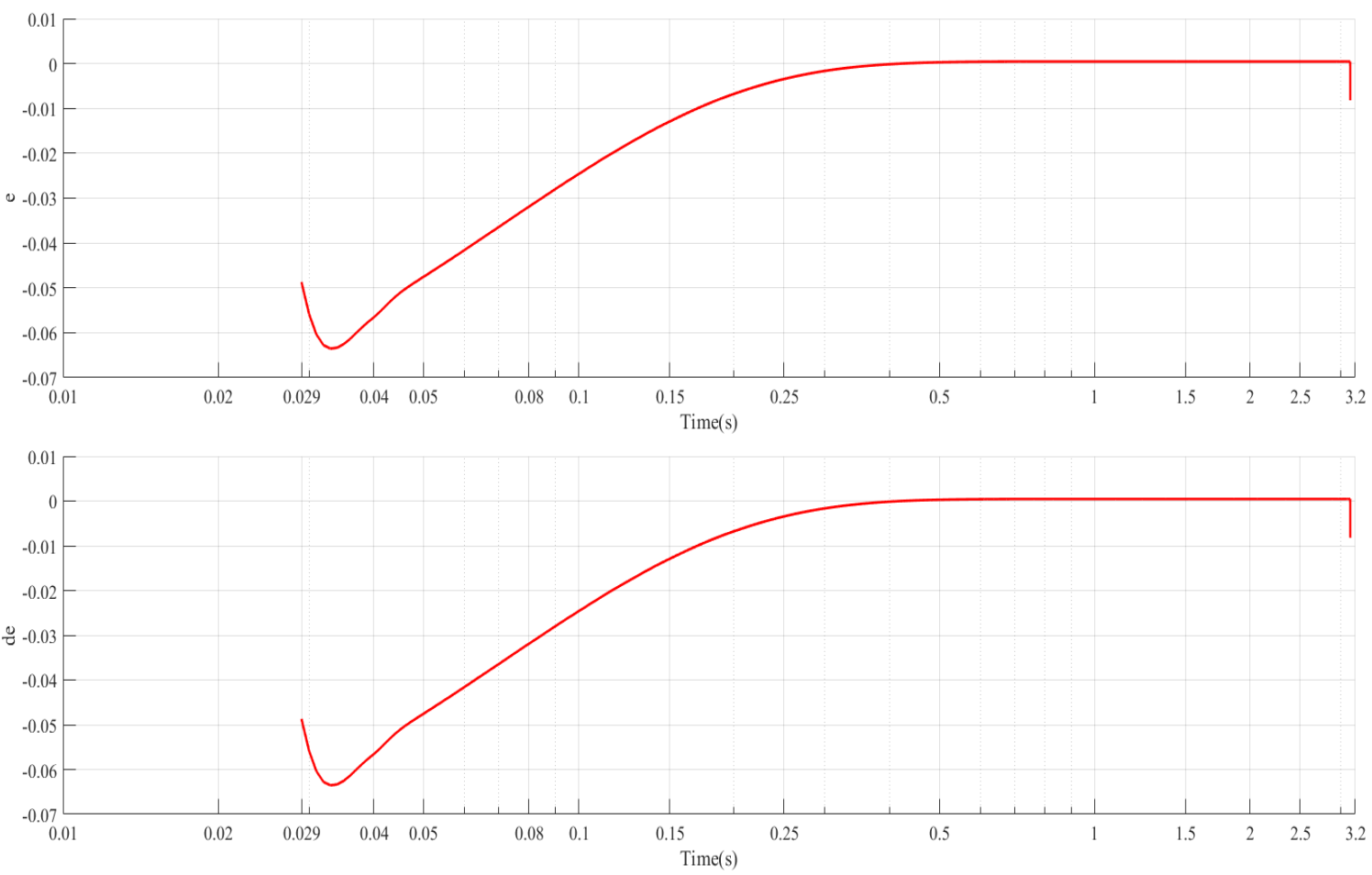

Figure 12. The wheel slip ratio error: $e=\lambda_{o}-\lambda_{t}$ and de with adaptive capability.
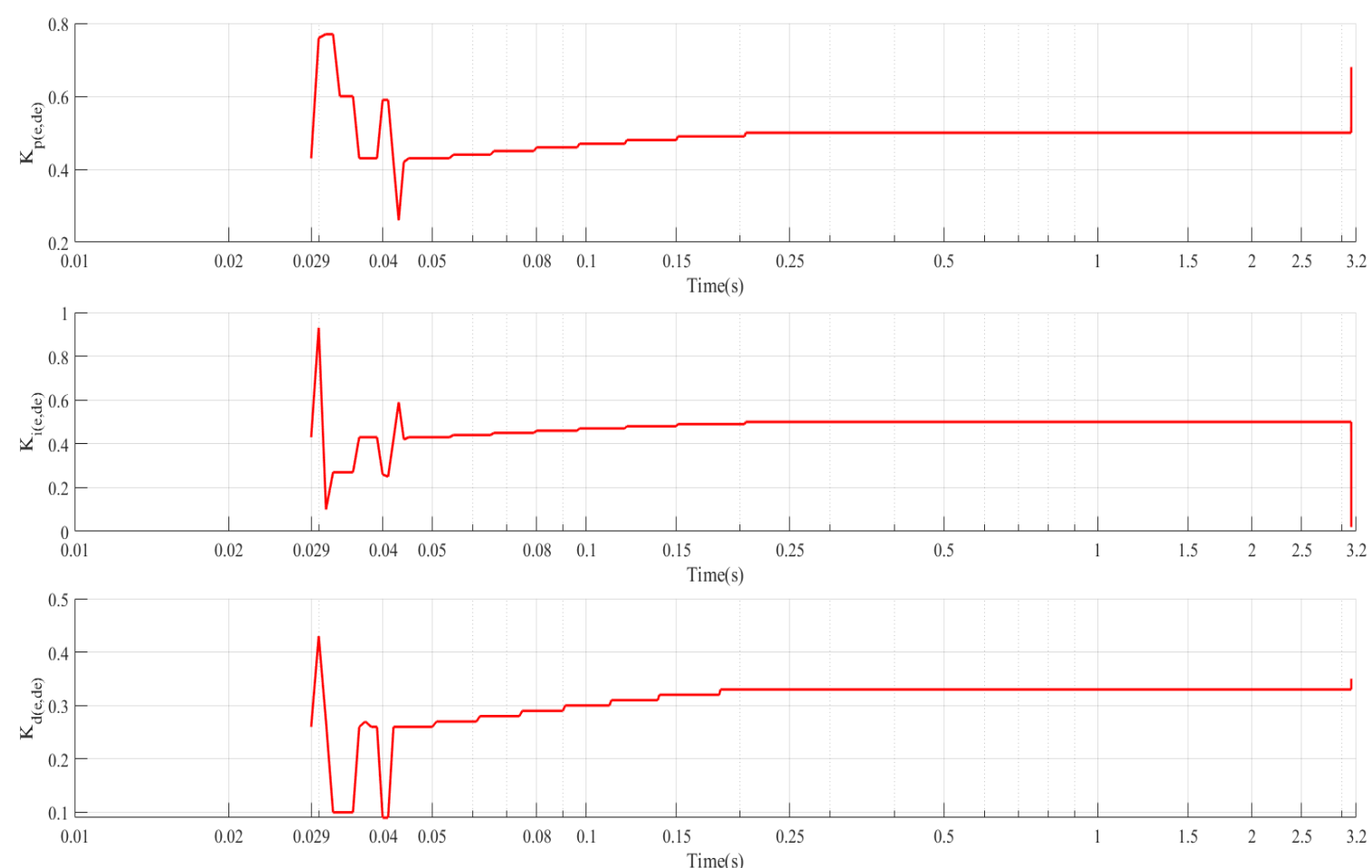

Figure 13. Fuzzy control output parameters: $K_{p(e, \dot{e})}, K_{i(e, \dot{e})}$ and $K_{d(e, \dot{e})}$ with adaptive capability. 
Select $v_{0}=100 \mathrm{~km} / \mathrm{h}$ and dry road as an example to describe the whole braking process, which control details are shown in Figure 14. The road condition automatic detection module firstly works and gives the road condition after the calculation period $\Delta t$. Then the SMWSC starts to adjust the $T_{b w}$ and lets the vehicle drive under the stable anti-lock braking situation until it stops.
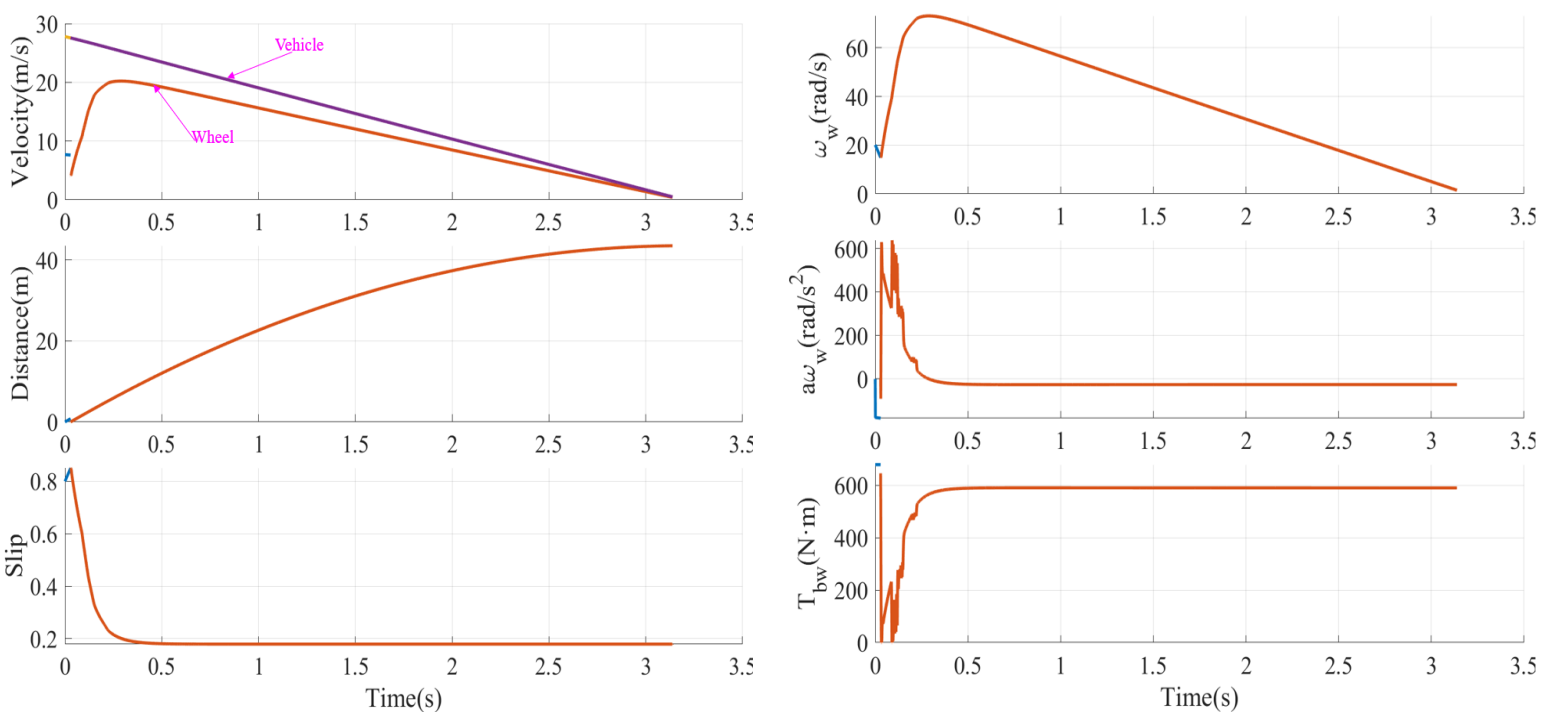

Figure 14. SMWSC control on dry roads with $v_{0}=100 \mathrm{~km} / \mathrm{h}$.

Figure 15 shows the adaptive changes of sliding mode surfaces during the whole ABS control period. In addition, Figure 16 shows the parameter change details of the sliding model control module.
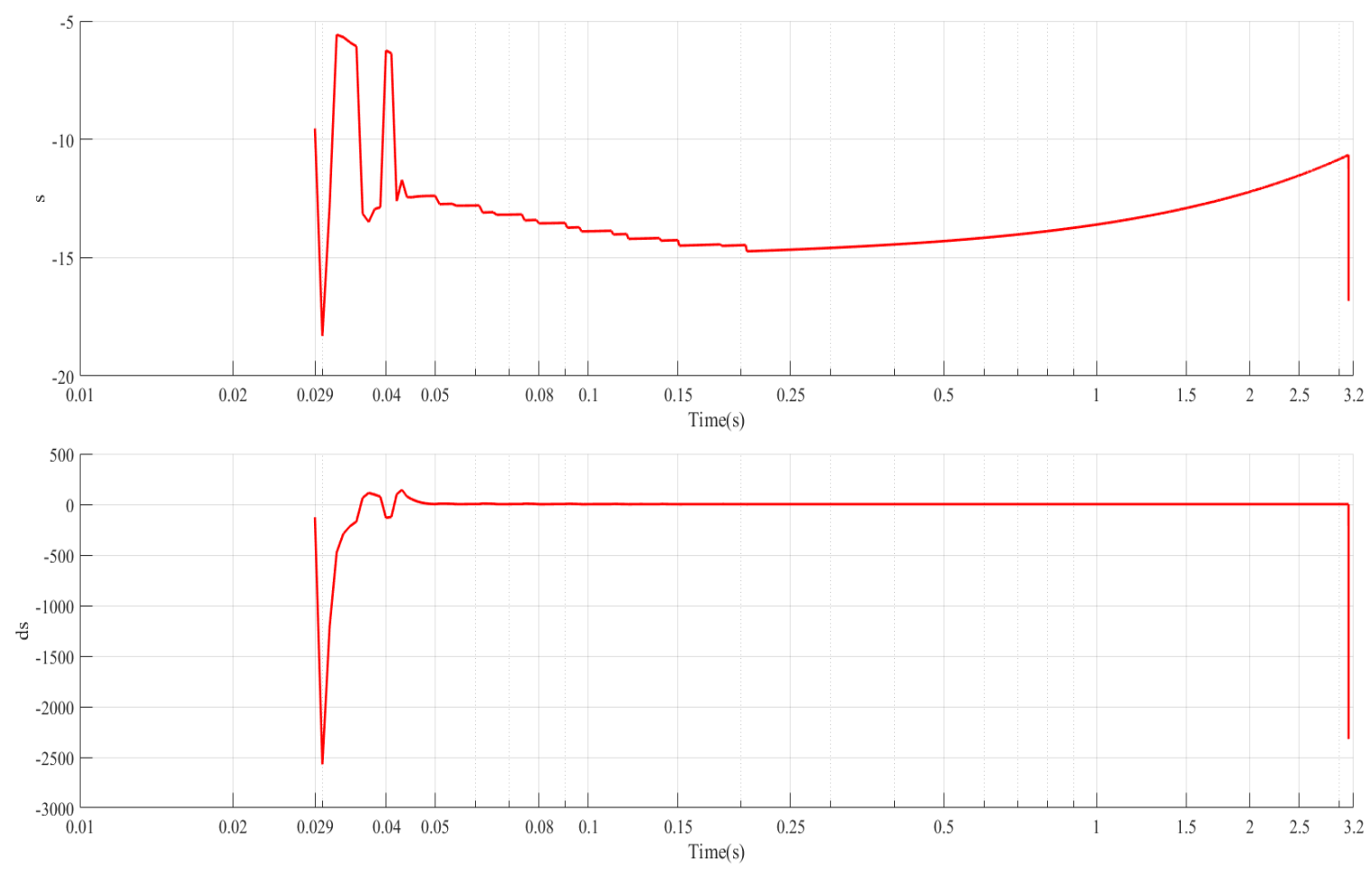

Figure 15. The adaptive sliding surface. 

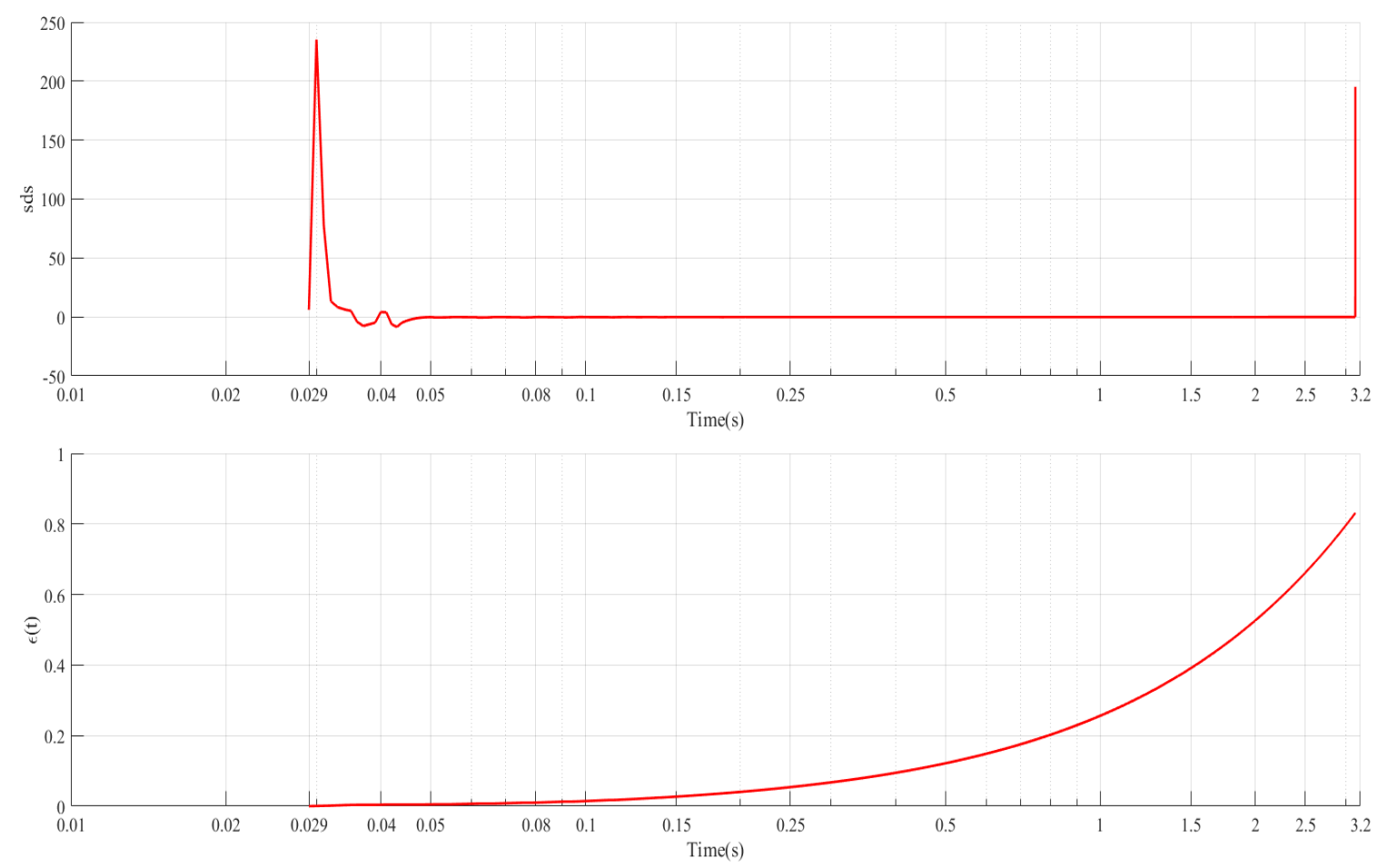

Figure 16. The output parameters of fuzzy sliding control module.

\section{Conclusions}

An SMWSC is proposed in this paper to yield optimal braking performance of a vehicle, which has the capability to ensure the vehicle not to skid during braking and shorten the stop distance on certain road conditions. Compared to the delay of traditional hydraulic ABSs, this pure electric braking system can quickly process the brake signal, which largely improves the EV's braking performance. Moreover, this proposed ABS controller contains the road detection module, which improves the intelligent feature of the braking process. This SMWSC can avoid the out-of-control direction and wheel side slip ratio during an emergency brake, so that the wheel will not be locked when braking. The tire is not allowed to rub against the ground at one point of the wheel, thereby increasing friction and braking efficiency.

In addition, after analysis of the $\mu(\lambda)$ curve's horizontal and vertical changes, this SMWSC is verified and has the capability to overcome disturbances on road conditions and vehicle mass. While this proposed ABS controller has advantages for improved braking performance, its limitations exist, such as when the vehicle with SMWSC brakes on an ice road, and its ability on the adjustment range of the braking force is not ideal.

Moreover, the assumptions, limitations, and relative merits of the proposed method in comparison with other conventional methods currently used in real applications are shown in the below description.

- The assumptions: This proposed ABS controller is designed based on a straight-line case. Besides, real existing forces and real initial braking situations are all considered in the initial state of wheel slip ratio and vehicle braking torque state.

- The limitations: This sliding mode wheel slip controller is firstly established based on vehicle parameters, such as $\mu(\lambda)$ curve and vehicle mass, but then there are simulations to verify the effect of these parameters on the control effect. Through simulation results comparison, this control algorithm is verified to have enough robustness capability to resist these parameters' disturbances.

- The relative merits: This proposed ABS controller has the road condition automatic detection module, which is new to the existing ABS controllers and can largely improve the intelligence performance. 
The wear on tires, which may influence the change of adhesion and friction, and the mechanical structure, which may impact the adjustment of braking torque, will be considered in further studies and real experiments $[29,30]$.

Author Contributions: J.S. developed the SMWSC algorithm, simulated the approach and wrote the manuscript. X.X. and K.W.E.C. directed the overall project. K.W.E.C. reviewed and edited the manuscript. All authors discussed the results and commented on the manuscript.

Funding: This study is sponsored by ITF-APAS of Hong Kong Government under the project: The Development and Application of All Electric Intelligent Anti-lock Braking System for Electric Vehicles, GHP/033/17AP.

Conflicts of Interest: The authors declare no conflict of interest.

\section{Appendix A}

Table A1. Variables and parameters of SMWSC for BYD F0.

\begin{tabular}{ccc}
\hline Sign & Parameter & Value \\
\hline$D(\mathrm{~m})$ & stop distance of vehicle & - \\
$\lambda$ & longitudinal wheel slip ratio & - \\
$v_{v_{x}}(\mathrm{~m} / \mathrm{s})$ & vehicle longitudinal velocity & - \\
$\omega_{w}(\mathrm{rad} / \mathrm{s})$ & wheel angular speed & - \\
$\mu$ & friction coefficient of road & - \\
$\mu_{r f}$ & wheel rolling friction coefficient & 0.015 \\
$\mu_{d}$ & friction coefficient of braking disc & $2 \times 0.38($ two discs $)$ \\
$M(\mathrm{~kg})$ & full mass of vehicle & $938($ with two persons $)$ \\
$R_{w}(\mathrm{~m})$ & wheel radius & 0.2768 \\
$R_{d}(\mathrm{~m})$ & radius of braking disc & 0.1025 \\
$m_{w}(\mathrm{~kg})$ & mass of wheel & 12 \\
$J\left(\mathrm{~kg} / \mathrm{m}{ }^{2}\right)$ & wheel inertia & $m_{w} \cdot R_{w}^{2}$ \\
$F_{a i r}(\mathrm{~N})$ & drag force from air & - \\
$\rho\left(\mathrm{kg} / \mathrm{m}{ }^{3}\right)$ & air density & 1.25 \\
$C_{a i r}$ & air resistance coefficient & 0.23 \\
$A_{a i r}\left(\mathrm{~m}^{2}\right)$ & air resistance area & $1.618 \times 1.465$ \\
$F_{f f w}(\mathrm{~N})$ & friction force of single wheel & $\mu \cdot M \cdot g / 4$ \\
$F_{r f w}(\mathrm{~N})$ & rolling friction force of single wheel & $\mu_{r f} \cdot M \cdot g / 4$ \\
$F_{p}(\mathrm{~N})$ & friction force from two pads & $2 \times \mu_{d} \cdot F_{a}$ \\
$F_{a}(\mathrm{~N})$ & required actuator force & $T_{b w} /\left(2 \times R_{d} \cdot \mu_{d}\right)$ \\
$T_{b w}(\mathrm{~N} \cdot \mathrm{m})$ & braking torque of single wheel & $R_{d} \cdot F_{p}$ \\
\hline &
\end{tabular}

\section{References}

1. Satzger, C.; Castro, R.D. Predictive brake control for electric vehicles. IEEE Trans. Veh. Technol. 2018, 67, 977-990. [CrossRef]

2. Castillo, J.J.; Cabrera, J.A.; Guerra, A.J.; Simón, A. A Novel Electrohydraulic Brake System With Tire-Road Friction Estimation and Continuous Brake Pressure Control. IEEE Trans. Ind. Electron. 2016, 63, 1863-1875. [CrossRef]

3. Yuan, Y.; Zhang, J.Z.; Li, Y.T.; Li, C. A Novel Regenerative Electrohydraulic Brake System: Development and Hardware-in-Loop Tests. IEEE Trans. Veh. Technol. 2018, 67, 11440-11452. [CrossRef]

4. Zhai, L.; Sun, T.M.; Wang, J. Electronic Stability Control Based on Motor Driving and Braking Torque Distribution for a Four In-Wheel Motor Drive Electric Vehicle. IEEE Trans. Veh. Technol. 2016, 65, 4726-4739. [CrossRef]

5. Zhou, Y.; Cheng, K.W.E.; Ho, J.F.; Huang, S.D.; Pan, J.F. A New Decoupled RotLin Motor With Fuzzy Sliding Mode Control. IEEE Trans. Magnet. 2018, 54, 1-5.

6. Wang, Y.F.; Fujimoto, H.; Hara, S.J. Driving Force Distribution and Control for EV With Four In-Wheel Motors: A Case Study of Acceleration on Split-Friction Surfaces. IEEE Trans. Ind. Electron. 2017, 64, 380-388. [CrossRef]

7. Xue, X.D.; Cheng, K.W.E.; Ng, T.W.; Cheng, N.C. Multi-Objective Optimization Design of In-Wheel Switched Reluctance Motors in Electric Vehicles. IEEE Trans. Ind. Electron. 2010, 57, 2980-2987. [CrossRef] 
8. Zhang, L.; Yu, L.Y.; Wang, Z.Z.; Zuo, L.; Song, J. All-Wheel Braking Force Allocation During a Braking-in-Turn Maneuver for Vehicles With the Brake-by-Wire System Considering Braking Efficiency and Stability. IEEE Trans. Veh. Technol. 2016, 65, 4752-4767. [CrossRef]

9. Zhang, C.Z.; Hu, J.F.; Qiu, J.B.; Yang, W.L.; Sun, H.; Chen, Q.J. A Novel Fuzzy Observer-Based Steering Control Approach for Path Tracking in Autonomous Vehicles. IEEE Trans. Ind. Electron. 2019, 27, 278-290. [CrossRef]

10. Pacejka, H.B. Tire and Vehicle Dynamics, 3rd ed.; Elsiever/Butterworth-Heinemann: Amsterdam, The Netherlands, 2012.

11. Wang, N.; Er, M.J.; Sun, J.C.; Liu, Y.C. Adaptive Robust Online Constructive Fuzzy Control of a Complex Surface Vehicle System. IEEE Trans. Cybern. 2016, 46, 1511-1523. [CrossRef]

12. Zhang, Z.S.; Ma, R.H ; Wang, L.F.; Zhang, J.Z. Novel PMSM Control for Anti-Lock Braking Considering Transmission Properties of the Electric Vehicle. IEEE Trans. Veh. Technol. 2018, 67, 10378-10386. [CrossRef]

13. Dadashnialehi, A.; Hadiashar, A.B.; Cao, Z.W.; Kapoor, A. Intelligent Sensorless ABS for In-Wheel Electric Vehicles. IEEE Trans. Ind. Electron. 2014, 61, 1957-1969. [CrossRef]

14. Ivanov, V.; Savitski, D.; Shyrokau, B. A Survey of Traction Control and Antilock Braking Systems of Full Electric Vehicles With Individually Controlled Electric Motors. IEEE Trans. Veh. Technol. 2015, 64, 3878-3896. [CrossRef]

15. Wei, Z.; Guo, X.X. An ABS Control Strategy for Commercial Vehicle. IEEE/ASME Trans. Mechatron. 2015, 20, 384-392. [CrossRef]

16. Feng, J.W.; Bao, C.J.; Wu, J.; Cheng, S.; Xu, G.F.; Liu, S.F. Research on Methods of Active Steering Control Based on Receding Horizon Control. Energies 2018, 11, 2243. [CrossRef]

17. Chen, Y.F.; Chen, I.M.; Chang, J.S.; Liu, T. Design and Analysis of a New Torque Vectoring System with a Ravigneaux Gearset for Vehicle Applications. Energies 2017, 10, 2157. [CrossRef]

18. Romijn, C.; Donkers, T.; Kessels, J.; Weiland, S. Real-Time Distributed Economic Model Predictive Control for Complete Vehicle Energy Management. Energies 2017, 10, 1096. [CrossRef]

19. Peng, J.K.; He, H.W.; Feng, N.L. Simulation Research on an Electric Vehicle Chassis System Based on a Collaborative Control System. Energies 2013, 6, 312-328. [CrossRef]

20. Cao, W.H.; Liu, H.L.; Lin, C.; Chang, Y.H.; Liu, Z.Y.; Antoni, S. Co-Design Based Lateral Motion Control of All-Wheel-Independent-Drive Electric Vehicles with Network Congestion. Energies 2017, 10, 1641. [CrossRef]

21. Xue, X.D.; Cheng, K.W.E.; Ho, S.L. Optimization and Evaluation of Torque-Sharing Functions for Torque Ripple Minimization in Switched Reluctance Motor Drives. IEEE Trans. Veh. Technol. 2009, 24, 2076-2090. [CrossRef]

22. Sun, H.Z.; Wang, H.; Zhao, X.C. Line Braking Torque Allocation Scheme for Minimal Braking Loss of Four-Wheel-Drive Electric Vehicles. IEEE Trans. Veh. Technol. 2019, 68, 180-192. [CrossRef]

23. Takagi, T.; Sugeno, M. Fuzzy identification of systems and its applications to modeling and control. IEEE Trans. Syst. 1985, 15, 116-132. [CrossRef]

24. Peng, X.Y.; Jia, M.F.; He, L; Yu, X.; Lv, Y.B. Fuzzy sliding mode control based on longitudinal force estimation for electro-mechanical braking systems using BLDC motor. CES Trans. Electr. Mach. Syst. 2018, 2, 142-151.

25. Mirzaei, M; Mirzaeinejad, H. Fuzzy Scheduled Optimal Control of Integrated Vehicle Braking and Steering Systems. IEEE/ASME Trans. Mechatron. 2017, 22, 2369-2379. [CrossRef]

26. Guillaume, S. Designing fuzzy inference systems from data: An interpretability-oriented review. IEEE Trans. Fuzzy Syst. 2001, 9, 426-443. [CrossRef]

27. Savitski, D.; Schleinin, D.; Ivanov, V.; Augsburg, K. Robust Continuous Wheel Slip Control With Reference Adaptation: Application to the Brake System With Decoupled Architecture. IEEE Trans. Ind. Inform. 2018, 14, 4212-4223. [CrossRef]

28. Xue, X.D.; Cheng, K.W.E.; Ho, S.L. A Self-Training Numerical Method to Calculate the Magnetic Characteristics for Switched Reluctance Motor Drives. IEEE Trans. Magn. 2004, 40, 734-737. [CrossRef] 
29. Vakis, A.I.; Yastrebov, V.A.; Scheibert, J.; Nicola, L.; Dini, D.; Minfray, C.; Molinari, J.F. Modeling and simulation in tribology across scales: An overview. Tribol. Int. 2018, 125, 169-199. [CrossRef]

30. Papangelo, A.; Ciavarella, M.; Hoffmann, N. Subcritical bifurcation in a self-excited single-degreeof-freedom system with velocity weakening strengthening friction law: Analytical results and comparison with experiments. Nonlinear Dyn. 2017, 90, 2037-2046. [CrossRef]

(c) 2019 by the authors. Licensee MDPI, Basel, Switzerland. This article is an open access article distributed under the terms and conditions of the Creative Commons Attribution (CC BY) license (http:/ / creativecommons.org/licenses/by/4.0/). 